\title{
SOLOS VERMELHOS E AMARELOS COESOS DE TABULEIROS COSTEIROS: GÊNESE, EVOLUÇÃO E INFLUÊNCIA DA NEOTECTÔNICA
}

Fábio Carvalho Nunes

Prof. Dr. Instituto Federal de Educação, Ciência e Tecnologia Baiano, Campus Santa Inês, Direção Acadêmica fcnunes76@gmail.com

Claudia Csekö Nolasco de Carvalho

Profa. Dra. Universidade Estadual de Alagoas, Departamento de Ciências Biológicas ccseko@hotmail.com

Geraldo da Silva Vilas Boas

Prof. Titular Aposentado Departamento de Sedimentologia gsvboas@gmail.com

Enio Fraga da Silva Pesquisador Empresa Brasileira de Pesquisa Agropecuária, Centro Nacional de Pesquisa de Solos enio.fraga@embrapa.br

Álvaro Luiz Mafra Luiz Mafra

Prof. Dr. Universidade do Estado de Santa Catarina, Centro Agroveterinário, Curso de Agronomia. alvaro.mafra@udesc.br

José Jackson Andrade

Prof. Ms. Universidade Católica de Salvador, Departamento de Geografia jose.andrade@ucsal.br

Saulo Roberto de Oliveira Vital

Prof. Dr. Universidade Federal do Rio Grande do Norte, Departamento de Geografia saulo@ceres.ufrn.br

\begin{abstract}
RESUMO
Os Tabuleiros Costeiros constituem uma unidade geomorfológica desenvolvida sobre o Grupo Barreiras, que apresenta grande extensão territorial e solos que sustentam diversas atividades produtivas, dentre elas a silvicultura e a citricultura. Os solos dos Tabuleiros Costeiros apresentam limitações físicas e químicas pouco entendidas, o que justifica ainda a realização de estudos genéticos. Por isso, estudou-se a origem e evolução de solos vermelhos e amarelos através de uma topossequência no Litoral Norte do estado da Bahia, bem como os mecanismos envolvidos na conformação de horizontes coesos. Os dados indicam que os solos vermelhos se formaram a partir de arenitos lamosos conglomeráticos e arenitos lamosos do Grupo Barreiras e se transformaram em amarelos. A gênese dos solos vermelhos foi acompanhada pela conformação de horizontes coesos, que se tornaram mais endurecidos e espessos com a evolução da cobertura pedológica para amarela, o que ocorreu pari passu com a diminuição dos teores de ferro livre, degradação do plasma argiloso dos horizontes superficiais e avanço da argiluviação. Atualmente, a topossequência está passando por um processo de podzolização, devido à influência da neotectônica, responsável pela formação de uma depressão fechada que acumula água após episódios de chuva, criando um ambiente hidromórfico temporário que acentua a degradação das argilas dos horizontes superficiais.
\end{abstract}

Palavras-chave: Grupo barreiras. Xantização. Horizonte coeso. Neotectônica.

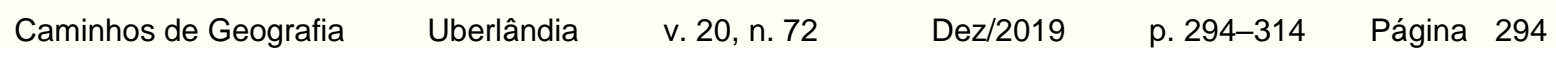


RED AND YELLOW SOILS COHESES OF COASTAL TABLELANDS: GENESIS, EVOLUTION AND INFLUENCE OF NEOTECTONICS

\begin{abstract}
The Coastal Tablelands is a geomorphological unit developed on the Barreiras Group, which has a large area and soils that support various productive activities, such as forestry and citrus. The soils of the Coastal Tablelands present physical and chemical limitations poorly understood, which further justify the need for genetic studies. Therefore, we studied the origin and evolution of red and yellow soils across a toposequence on the northern coast of Bahia state, as well as mechanisms involved in the formation of cohesive horizons. We conclude that the red soils formed from muddy conglomeratic sandstones and muddy sandstones Barreiras Group and became yellow soils. The genesis of red soils was accompanied by the formation of cohesive horizons, which have become more hardened and thick with the evolution of soils to yellow, which occurred with a decrease in the levels of free iron, clay degradation of surface horizons and advancing argilluviation. The topossequence is currently undergoing a process of podzolization, due to the influence of neotectonics, responsible for the formation of a closed depression that accumulates water after rain episodes, creating a temporary hydromorphic environment and accentuating the clays degradation of the superficial horizons.
\end{abstract}

Keywords: Barreiras group. Xanthization. Cohesive horizon. Neotectonic.

\title{
INTRODUÇÃO
}

O Grupo Barreiras constitui uma cobertura sedimentar essencialmente siliciclástica, de origem continental e marinha, de idade compreendida entre o Mioceno inferior/médio e o Plioceno (VILAS BOAS et al. 2001; ARAI, 2006), sobre o qual se desenvolveram superfícies tabuliformes denominadas de Tabuleiros Costeiros (ROSSETTI e DOMINGUEZ, 2012). Os Tabuleiros Costeiros despertam grande interesse econômico e científico, uma vez que possuem grande extensão territorial e apresentam condições topográficas, climáticas e hídricas de superfície e subsuperfície favoráveis ao uso agrícola. Além disso, sustentam importantes remanescentes da Mata Atlântica e muitos centros urbanos e capitais de estados estão localizados em seus domínios ou adjacências, sendo que em alguns estados do nordeste apresentam as melhores áreas para o uso agrícola.

Nos Tabuleiros Costeiros predominam os Latossolos Amarelos, seguidos pelos Argissolos Amarelos, Argissolos Acinzentados e Espodossolos, expressando que os principais processos pedogenéticos que se desenvolvem são a latolização, argiluviação e podzolização. Contudo, estudos acurados revelam a complexidade dos mecanismos envolvidos na formação e evolução dos solos desenvolvidos sobre o Grupo Barreiras, dentre eles, Dubroeucq e Volkoff (1998) e Corrêa et al. (2008).

Embora esclarecimentos sobre os solos de Tabuleiros Costeiros tenham sido obtidos no decorrer dos últimos anos, estudos pedogenéticos complementares são necessários, em especial sobre os solos vermelhos, horizontes coesos e camadas cimentadas, devido às controvérsias observadas na literatura. Dentro desse contexto, o presente trabalho investigou a gênese e evolução de solos vermelhos e amarelos coesos de Tabuleiros Costeiros no Litoral Norte do estado da Bahia.

\section{MATERIAL E MÉTODOS}

Os estudos foram realizados no município de Entre Rios (Figura 1), na fazenda Rio Negro, de propriedade da Bahia Pulp, e no seu entorno. A área está sob condições climáticas úmidas, com estação chuvosa de

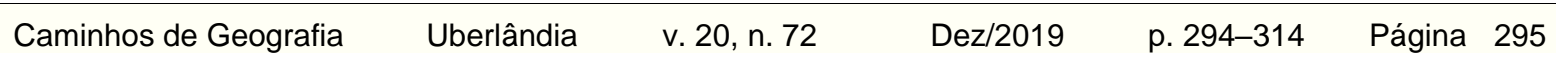


Fábio Carvalho Nunes

Claudia Csekö Nolasco de Carvalho

Geraldo da Silva Vilas Boas

Enio Fraga da Silva

Solos vermelhos e amarelos coesos de Tabuleiros

Álvaro Luiz Mafra Luiz Mafra

José Jackson Andrade

Costeiros: gênese, evolução e influência da neotectônica Saulo Roberto de Oliveira Vital

outono-inverno, temperaturas médias anuais superiores $24^{\circ} \mathrm{C}$ e vegetação original Floresta Tropical Subcaducifólia (BRASIL, 1981).

Figura 1 - Mapa da área de estudos.

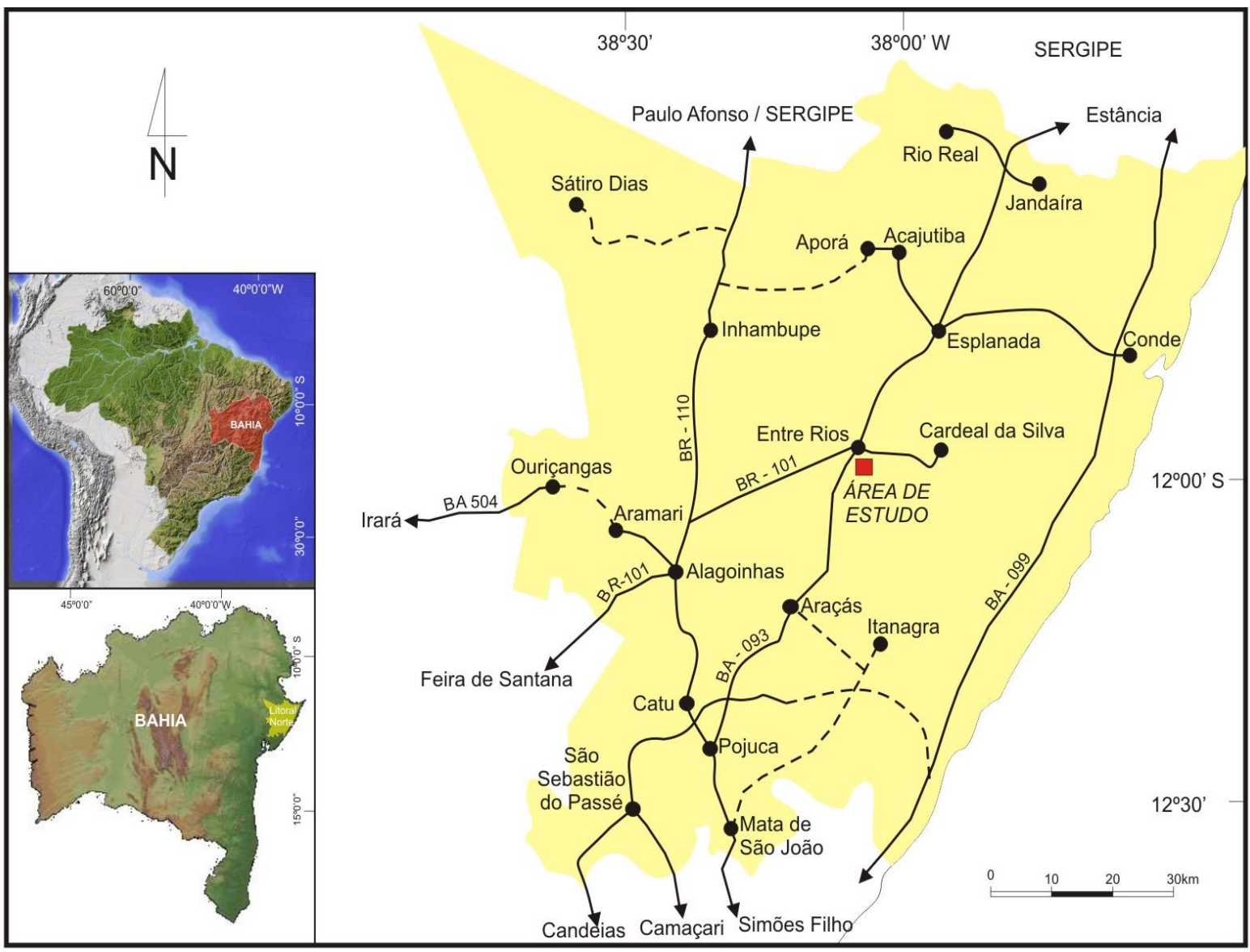

A geologia é composta por litotipos do Grupo Barreiras, a saber, diamictitos, arenitos lamosos e argilitos, sobre os quais se desenvolveram modelados de dissecação homogênea, com feições aplanadas parcialmente conservadas tendendo a formar colinas convexas. Os solos da área são: os Argissolos Amarelos, presentes nos topos e nas encostas; Espodossolos no topo sob depressões fechadas; Argissolos Acinzentados no entorno de algumas depressões fechadas; Latossolos Vermelhos, Argissolos Vermelhos, Cambissolos Háplicos e Neossolos Litólicos a partir de ombreiras de vertentes e; Latossolos Amarelos, que aparecem como inclusões em alguns topos.

Escolheu-se uma topossequência de solos com 84 metros de extensão e quatro perfis de solos (Figura 2), onde foram realizadas análises morfológicas, granulométricas, químicas, mineralógicas e micromorfológicas, conforme Santos et al. (2013) e Embrapa (2011).

As análises mineralógicas foram realizadas por Difratometria de Raios-X, radiação CuK $\square(\square=0,154 \mathrm{~nm})$, sem filtro com monocromador de grafite, fendas $1,25^{\circ} \mathrm{DS}, 0,3 \mathrm{~mm} \mathrm{RS}, 1,25^{\circ} \mathrm{SS}$, energia de irradiação 30 $\mathrm{kV}$ e $15 \mathrm{~mA}$, intervalo de varredura $2^{\circ}$ a $45^{\circ}(2 \square)$, unidade de contagem cps, constante de tempo 1 seg., passo $0,050^{\circ}$. Utilizou-se o Microscópio Eletrônico de Varredura (MEV) com o objetivo de analisar constituintes mineralógicos e a estrutura micropedológica de horizontes coesos.

$\begin{array}{llllll}\text { Caminhos de Geografia } & \text { Uberlândia } & \text { v. 20, n. } 72 & \text { Dez/2019 } & \text { p. 294-314 Página } 296\end{array}$


Fábio Carvalho Nunes

Claudia Csekö Nolasco de Carvalho

Geraldo da Silva Vilas Boas

Enio Fraga da Silva

Solos vermelhos e amarelos coesos de Tabuleiros

Álvaro Luiz Mafra Luiz Mafra

José Jackson Andrade

Costeiros: gênese, evolução e influência da neotectônica Saulo Roberto de Oliveira Vital

Figura 2 - Topossequência de solos estudada.

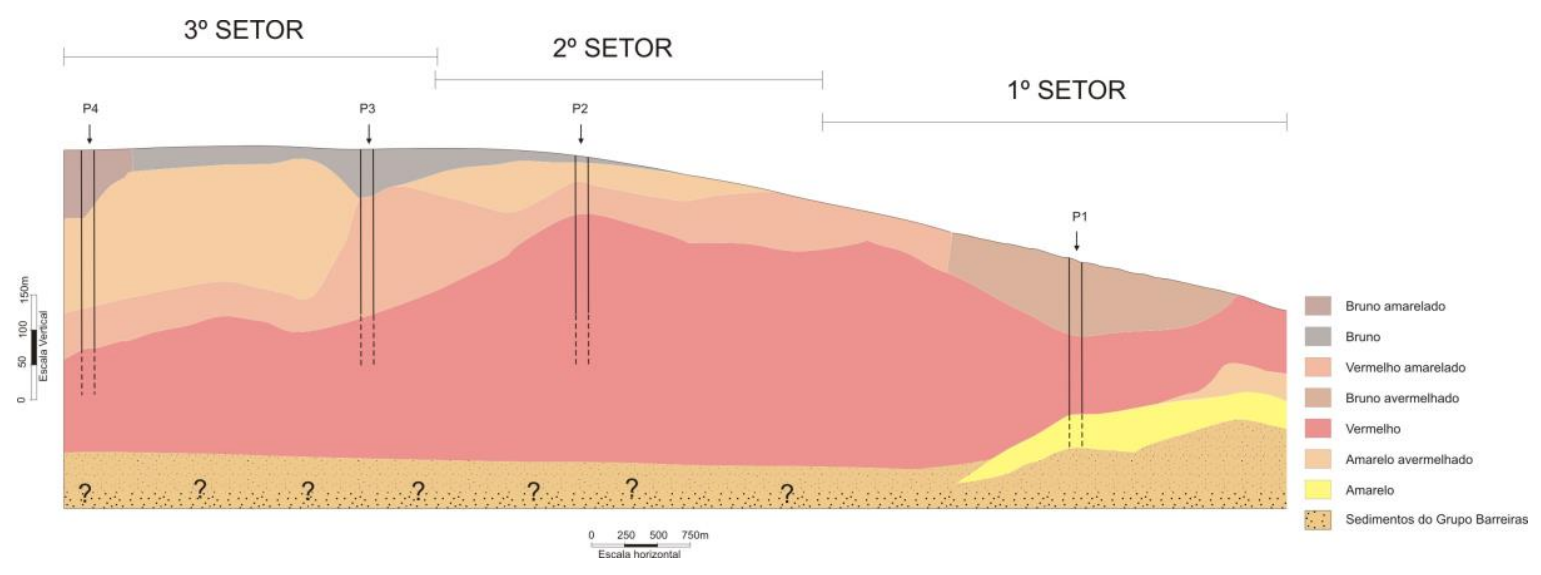

A caracterização geológica da área foi realizada através da descrição de perfis litológicos e a análise estrutural foi realizada através de fotointerpretação.

\section{RESULTADOS E DISCUSSÃO}

\section{ATRIBUTOS MORFOLÓGICOS E GRANULOMÉTRICOS}

O Perfil P1 é um CAMBISSOLO HÁPLICO Tb Distrófico típico desenvolvido sobre diamictito ferruginoso sotoposto a arenito lamoso com setores conglomeráticos, localizado na encosta da vertente, apresenta sequência horizontes $\mathrm{A}$, Bix, $\mathrm{C} 1,2 \mathrm{C} 2,2 \mathrm{C} 3$ e cores que variam de bruno-avermelhado em superfície para vermelho em subsuperfície (Quadro 1). A textura é franco-argiloarenosa no horizonte A, com incremento de argila no horizonte Bix, comportamento similar ao da argila dispersa, que possui um acréscimo superior a $25 \%$ do horizonte A para o Bix (Quadro 2) e representa 36\% da argila total desse horizonte. O aspecto moderadamente maciço coeso aparece no horizonte $\mathrm{Bix}$, às vezes se confundindo com relictos do diamictito ferruginoso. Nos horizontes $\mathrm{C} 1,2 \mathrm{C} 2$ e $2 \mathrm{C} 3$ aparece o aspecto maciço poroso, o qual apresenta volumes do arenito lamoso conglomerático no horizonte $\mathrm{C} 1$ e do arenito lamoso no $2 \mathrm{C} 2$ e $2 \mathrm{C} 3$ em diferentes estádios de alteração.

O Perfil P2 é um ARGISSOLO VERMELHO-AMARELO Distrófico típico desenvolvido sobre arenito lamoso ferruginoso, localizado na ombreira da vertente, possui sequência horizontes $A p, B A x, B t \times 1, B t x 2$, $\mathrm{C} 1, \mathrm{C} 2$ e cores que variam de bruno em superfície para vermelho em subsuperfície. A textura é francoargiloarenosa em superfície, com acréscimo gradual de argila até o horizonte Btx2, comportamento similar ao da argila dispersa, que possui um acréscimo superior a 90\% do horizonte Ap para o Btx2 e representa mais de $45 \%$ da argila total. O aspecto fortemente coeso aparece no horizonte BAx e se expressa até Btx2.

O Perfil P3 é um ARGISSOLO AMARELO Distrocoeso típico desenvolvido sobre arenito lamoso ferruginoso, localizado no ombro superior da vertente sob uma pequena depressão, com sequência de horizontes $\mathrm{A} 1, \mathrm{~A} 2, \mathrm{~A} 3, \mathrm{ABx}, \mathrm{Btx} 1, \mathrm{Btx} 2, \mathrm{C} 1, \mathrm{C} 2$ e com cores que variam de bruno em superfície para vermelho-amarelado em subsuperfície. O perfil apresenta mosqueados desde os horizontes superficiais até a uma profundidade de $150 \mathrm{~cm}$, por causa da hidromorfia temporária.

A textura é areia-franca no horizonte $A 1$ e franco-arenosa até uma profundidade de $46 \mathrm{~cm}$, com aumento gradual de argila até o horizonte Btx2. A argila dispersa possui comportamento similar, com um acréscimo de $200 \%$ do horizonte A1 para o Btx2. O solo apresenta o maior espessamento do horizonte coeso, e o 
Fábio Carvalho Nunes

Claudia Csekö Nolasco de Carvalho

Geraldo da Silva Vilas Boas

Enio Fraga da Silva

Solos vermelhos e amarelos coesos de Tabuleiros

Álvaro Luiz Mafra Luiz Mafra

José Jackson Andrade

Costeiros: gênese, evolução e influência da neotectônica

Saulo Roberto de Oliveira Vital

grau de coesão (é extremamente duro quando seco), aparece desde poucos centímetros da superfície e alcança profundidades superiores a $140 \mathrm{~cm}$.

Quadro 1 - Características morfológicas dos solos estudados.

\begin{tabular}{l|l|l|l|l|l|l|l}
\hline Horiz & $\begin{array}{l}\text { Prof } \\
(\mathrm{cm})\end{array}$ & $\begin{array}{c}\text { Cor } \\
\text { (úmido) }\end{array}$ & Estrutura & \multicolumn{3}{|c}{ Consistência } \\
\cline { 5 - 7 } & & & Seca & Úmida & Molhada & Tra \\
\hline
\end{tabular}

\begin{tabular}{|c|c|c|c|c|c|c|}
\hline \multirow[b]{2}{*}{ A } & \multicolumn{6}{|c|}{ P1 - CAMBISSOLO HÁPLICO Tb Distrófico típico } \\
\hline & $0-10$ & $5 Y R 5 / 4$ & 1PBls Gs & $\mathrm{Ma}$ & $\mathrm{Fr}$ & $\tilde{n} P I \tilde{n} P e$ \\
\hline$A B$ & $10-44$ & $5 Y R 5 / 4$ & 1PBls Ma & Ma D & $\mathrm{Fr}$ & LgPI LgPe \\
\hline Bix & $44-115$ & 2,5YR4/8 & $\mathrm{Ma}$ & D & $\mathrm{Fr}$ & LgPI LgPe \\
\hline $\mathrm{C}_{1}$ & 115-162 & 2,5YR4/8 & $\mathrm{Mp}$ & $\mathrm{Ma}$ & $\mathrm{Fr}$ & LgPI LgPe \\
\hline $2 \mathrm{C}_{2}$ & $162-232$ & 2,5YR4/8 & Mp & $\mathrm{Ma}$ & $\mathrm{Fr}$ & LgPI LgPe \\
\hline $2 \mathrm{C}_{3}$ & $232-250+$ & 2,5YR4/8, & Mp Gs & Ma So & Fr So & LgPI ñPe \\
\hline
\end{tabular}

\section{P2 - ARGISSOLO VERMELHO-AMARELO Distrófico típico}

\begin{tabular}{|c|c|c|c|c|c|c|}
\hline Ap & $0-18$ & 7,5 YR5/4 & 1PMBls Gs & $\mathrm{Ma}$ & $\mathrm{Fr}$ & LgPI LgPe \\
\hline $\mathrm{BAx}$ & $18-35$ & 7,5YR6/6 & 1PBls Ma & Ma MD & $\mathrm{Fr}$ & LgPI LgPe \\
\hline Btx 1 & $35-80$ & 7,5YR7/8 & $\mathrm{Ma}$ & MD & $\mathrm{Fr}$ & LgPI LgPe \\
\hline $\mathrm{Btx} 2$ & $80-115$ & 2,5YR5/8 & $\mathrm{Ma}$ & MD & $\mathrm{Fi}$ & LgPI LgPe \\
\hline$C_{1}$ & $115-180$ & $2,5 Y R 5 / 8$ & Mp 1PBls 2MPGr & $\mathrm{Ma}$ & Fr MFr & $\mathrm{PIPe}$ \\
\hline $\mathrm{C}_{2}$ & $180-220+$ & 2,5YR5/8 & Mp 1PBls 2MPGr & $\mathrm{Ma}$ & Fr MFr & $\mathrm{PIPe}$ \\
\hline
\end{tabular}

P3 - ARGISSOLO AMARELO Distrocoeso típico

\begin{tabular}{|c|c|c|c|c|c|c|}
\hline$A_{1}$ & $0-7$ & $7,5 Y R 4 / 2$ & Gs 1 PBls & So Ma & So $\mathrm{Fr}$ & $\tilde{n} P I \tilde{n} P e$ \\
\hline $\mathrm{A}_{2}$ & 7-17 & 7,5YR4/4 & $\mathrm{Ma}$ & D & $\mathrm{Fi}$ & LgPI LgPe \\
\hline $\mathrm{A}_{3}$ & $17-26$ & 7,5YR3/2 & $\mathrm{Ma}$ & D & $\mathrm{Fi}$ & LgPI LgPe \\
\hline$A B x$ & $26-46$ & 7,5YR5/2 & $\mathrm{Ma}$ & D & $\mathrm{Fi}$ & LgPI LgPe \\
\hline $\mathrm{Btx}{ }_{1}$ & $46-68$ & 7,5YR5/8 & $\mathrm{Ma}$ & MD & $\mathrm{Fi}$ & LgPI LgPe \\
\hline Btx 2 & $68-143$ & 7,5YR6/6 & $\mathrm{Ma}$ & MD & $\mathrm{Fr}$ & LgPI LgPe \\
\hline $\mathrm{C}_{1}$ & $143-215$ & 5YR5/8 & Mp 1PBls 2MPGr & $\mathrm{Ma}$ & $\mathrm{Fr}$ & LgPI LgPe \\
\hline $\mathrm{C}_{2}$ & $215-237+$ & 5YR5/8 & Mp 1PMBIs 2MPGr & $\mathrm{Ma}$ & $\mathrm{Fr}$ & LgPI LgPe \\
\hline
\end{tabular}

\begin{tabular}{|c|c|c|c|c|c|c|}
\hline \multicolumn{7}{|c|}{ P4 - ARGISSOLO AMARELO Distrocoeso abrúptico } \\
\hline $0-4$ & 10YR5/4 & Gs 1 PBls & So $\mathrm{Ma}$ & So MFr & $\tilde{n} P I \tilde{n} P e$ & ap \\
\hline 4-15 & 10YR5/4 & 1PBls & $\mathrm{Ma}$ & $\mathrm{Fr}$ & $\tilde{n} P I \tilde{n} P e$ & $\mathrm{cp}$ \\
\hline $15-30$ & 10YR $4 / 4$ & 1PBls & $\mathrm{Ma}$ & $\mathrm{Fr}$ & LgPI LgPe & \\
\hline $30-100$ & 10YR4/4 & $\mathrm{Ma}$ & MD & $\mathrm{Fi}$ & LgPI LgPe & $\mathrm{p}$ \\
\hline $100-162$ & 7,5YR6/8 & $\mathrm{Ma}$ & MD & $\mathrm{Fi}$ & LgPI LgPe & p \\
\hline 162-185 & 7,5YR6/8 & Mp 1PBIs 2MPGr & $\mathrm{Ma}$ & $\mathrm{Fr}$ & LgPI LgPe & p \\
\hline $185-215+$ & 5YR5/8 & Mp 1PMBls 2MPGr & $\mathrm{Ma}$ & $\mathrm{Fr}$ & LgPI LgPe & \\
\hline
\end{tabular}

Horiz - Horizonte; Prof - profundidade; Estrutura - 1; fraca; 2: forte; MP: muito pequena; P: pequena; M: média; G: grande; Gr: granular; Bls: blocos subangulares; Gs: grão simples. Ma: maciça. Mp: maciça porosa. Consistência: So: solto; Ma: macio; D: dura; MD: muito dura; MFr: muito friável; Fr: friável; Fi - firme; ñ: não; Lg: ligeiramente;

PI: plástico; Pe: pegajoso. Tra:Transição - a: abrupta; g: gradual; d: difusa; c: clara; p: plana.

O Perfil P4 é um ARGISSOLO AMARELO Distrocoeso abrúptico desenvolvido sobre arenito lamoso ferruginoso, localizado no topo da vertente, apresenta sequência horizontes A1, A2, A3, Btx1, Btx2, C1, C2

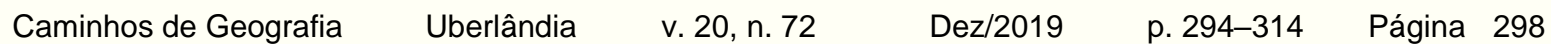


Fábio Carvalho Nunes

Claudia Csekö Nolasco de Carvalho

Geraldo da Silva Vilas Boas

Enio Fraga da Silva

Álvaro Luiz Mafra Luiz Mafra

José Jackson Andrade

Solos vermelhos e amarelos coesos de Tabuleiros Saulo Roberto de Oliveira Vital

com cores que variam de bruno-amarelado em superfície para vermelho-amarelado em subsuperfície. A textura é arenosa em superfície, com acréscimo gradual de argila até o horizonte Btx2, sendo que a argila dispersa possui um incremento superior a $300 \%$ do horizonte $\mathrm{A} 1$ para o Btx1, a qual representa $80 \%$ da argila total desse horizonte.

Quadro 2 - Caracterização física dos solos.

\begin{tabular}{|c|c|c|c|c|c|c|c|c|}
\hline \multirow[t]{2}{*}{ Horizonte } & \multirow{2}{*}{$\begin{array}{l}\text { Prof } \\
(\mathrm{cm})\end{array}$} & \multicolumn{4}{|c|}{ Composição granulométrica $(\mathrm{g} / \mathrm{kg})$} & \multirow{2}{*}{$\begin{array}{c}\text { Argila } \\
\text { disp }\end{array}$} & \multirow{2}{*}{$\begin{array}{c}\text { Floculação } \\
(\%)\end{array}$} & \multirow{2}{*}{$\frac{\text { Silte }}{\text { Argila }}$} \\
\hline & & $A G$ & $\mathrm{AF}$ & $\mathrm{S}$ & A & & & \\
\hline
\end{tabular}

\section{P1 - CAMBISSOLO HÁPLICO Tb Distrófico típico}

$\begin{array}{lrrrrrrrr}\text { A } & 0-10 & 424 & 279 & 34 & 263 & 110 & 54 & 0,13 \\ \mathrm{AB} & 10-44 & 385 & 282 & 31 & 302 & 140 & 33 & 0,10 \\ \mathrm{Bix} & 44-115 & 364 & 213 & 41 & 382 & 140 & 32 & 0,11 \\ \mathrm{C}_{1} & 115-162 & 410 & 215 & 33 & 342 & 0 & 100 & 0,10 \\ 2 \mathrm{C}_{2} & 162-232 & 404 & 247 & 27 & 322 & 0 & 100 & 0,08 \\ 2 \mathrm{C}_{3} & 232-250+ & 410 & 241 & 48 & 301 & 0 & 100 & 0,16\end{array}$

\section{P2 - ARGISSOLO VERMELHO-AMARELO Distrófico típico}

$\begin{array}{lrrrrrrrr}\text { Ap } & 0-18 & 420 & 340 & 39 & 201 & 110 & 50 & 0,19 \\ \text { BAx } & 18-35 & 305 & 269 & 62 & 364 & 180 & 17 & 0,17 \\ \text { Btx } 1 & 35-80 & 281 & 172 & 82 & 465 & 210 & 87 & 0,18 \\ \text { Btx }_{2} & 80-115 & 307 & 166 & 62 & 465 & 210 & 100 & 0,13 \\ \text { C }_{1} & 115-180 & 385 & 199 & 114 & 302 & 0 & 100 & 0,38 \\ \mathrm{C}_{2} & 180-220+ & 400 & 201 & 77 & 322 & 0 & 100 & 0,24\end{array}$

\section{P3 - ARGISSOLO AMARELO Distrocoeso típico}

$\begin{array}{lrrrrrrrr}\mathrm{A}_{1} & 0-7 & 450 & 370 & 60 & 120 & 70 & 41 & 0,5 \\ \mathrm{~A}_{2} & 7-17 & 340 & 400 & 90 & 170 & 110 & 35 & 0,5 \\ \mathrm{~A}_{3} & 17-26 & 340 & 360 & 70 & 230 & 140 & 39 & 0,3 \\ \mathrm{ABx} & 26-46 & 300 & 420 & 60 & 220 & 140 & 36 & 0,3 \\ \mathrm{Btx} 1 & 46-68 & 280 & 320 & 60 & 280 & 170 & 39 & 0,2 \\ \mathrm{Btx}{ }_{2} & 68-143+ & 360 & 230 & 80 & 410 & 210 & 49 & 0,2\end{array}$

\section{P4 - ARGISSOLO AMARELO Distrocoeso abrúptico}

\begin{tabular}{lrrrrrrrr}
$\mathrm{A}_{1}$ & $0-4$ & 467 & 394 & 38 & 101 & 60 & 41 & 0,38 \\
$\mathrm{~A}_{2}$ & $4-15$ & 443 & 317 & 138 & 102 & 61 & 40 & 1,35 \\
$\mathrm{~A}_{3}$ & $15-30$ & 432 & 406 & 22 & 140 & 80 & 43 & 0,16 \\
$\mathrm{Btx}_{1}$ & $30-100$ & 327 & 316 & 55 & 302 & 242 & 20 & 0,18 \\
$\mathrm{Btx}_{2}$ & $100-162$ & 391 & 222 & 24 & 363 & 0 & 100 & 0,07 \\
$\mathrm{C}_{1}$ & $162-185$ & 413 & 223 & 22 & 342 & 0 & 100 & 0,06 \\
$\mathrm{C}_{2}$ & $185-215+$ & 395 & 230 & 32 & 343 & 0 & 100 & 0,09 \\
\hline
\end{tabular}

Prof - Profundidade; AG- Areia grossa; AF- Areia fina; S- Silte; A- Argila.

Caminhos de Geografia Uberlândia $\quad$ v. 20, n. $22 \quad$ Dez/2019 $\quad$ p. 294-314 Página 299


Fábio Carvalho Nunes

Claudia Csekö Nolasco de Carvalho

Geraldo da Silva Vilas Boas

Enio Fraga da Silva

Solos vermelhos e amarelos coesos de Tabuleiros

Álvaro Luiz Mafra Luiz Mafra

Costeiros: gênese, evolução e influência da neotectônica

José Jackson Andrade

Saulo Roberto de Oliveira Vital

\section{ATRIBUTOS QUÍMICOS E MINERALÓGICOS}

Os solos são ácidos e possuem baixa CTC, os valores do Si e Al do ataque sulfúrico indicam a presença predominante de argila do tipo 1:1 e os teores de ferro são baixos, enquadrando-os como hipoférricos, sendo maiores nos solos vermelhos e avermelhados e inferiores nos solos amarelos (Quadro 3). Os resultados da DRX mostram a predominância da caulinita em todas as amostras (Figura 3), ocorrendo também quartzo, goethita, hematita e anatásio, sendo que goethita e hematita coexistem no solo vermelho (Figura 4).

\section{MICROMORFOLOGIA E SUBMICROSCOPIA}

\section{Perfil P1}

O horizonte 2C2 apresenta contextura porfírica aberta e setores quitônica, com esqueleto constituído de grãos de quartzo mal selecionados, subarredondados e arredondados, alguns nódulos ferruginosos subarredondados e vermelho-escuros (2,5YR 3/6) e relíquias de materiais micáceos (Quadro 4). Os nódulos estão em processo de degradação, originando a um plasma vermelho e amarelo-avermelhado (Figura 5ABCD).

No horizonte $\mathrm{C} 1$ a contextura é porfírica aberta, porfírica fechada e setores enáulica, com esqueleto de grãos de quartzo mal selecionados subarredondados e nódulos ferruginosos em diferentes estádios de degradação, originando um plasma vermelho e amarelado. No horizonte Bix a contextura é porfírica aberta, com setores quitônica e porfírica fechada, com esqueleto de grãos de quartzo mal selecionados subarredondados, nódulos ferruginosos menores e em estágio de degradação mais avançado. No horizonte $\mathrm{A}$ a microestrutura é quitônica com setores porfírica aberta, o esqueleto é constituído de grãos de quartzo mal selecionados, subarredondados, e nódulos ferruginosos onde prevalece a estrutura porfírica.

As amostras analisadas dos horizontes A, Bix, C1 e 2C2 estudadas utilizando o MEV mostram o predomínio de caulinitas arredondadas pequenas (entre $1 \mu$ e $0,2 \mu$ ) (Figura 5E), ocorrendo também frações menores que $0,2 \mu$ e maiores que $1 \mu$, contudo menos frequentes. Não foram identificados cristais de hematita e goethita, mesmo com o auxílio de elétrons retroespalhados (BEC), apenas zonas mais claras e brilhantes enriquecidas com ferro (Figura 5F), indicando que esses "óxidos" são criptocristalinos, uma vez que apresentam padrão de difração de raios-X. Compostos silico-aluminosos ou aluminosilicosos mal-cristalizados também foram identificados recobrindo o esqueleto quartzoso de algumas amostras, os quais mostram uma relação espacial e morfológica com o plasma caulinítico adjacente. À medida que aumenta a espessura dos revestimentos sobre os grãos de quartzo começa a surgir aglomerados com formato arredondado, típico das caulinitas (Figura 5GH). 
Quadro 3 - Caracterização química dos solos.

\begin{tabular}{|c|c|c|c|c|c|c|c|c|c|c|c|c|c|c|c|c|c|}
\hline \multirow[t]{2}{*}{ Horiz } & \multirow{2}{*}{$\begin{array}{l}\text { Prof. } \\
\text { (cm) }\end{array}$} & \multirow{2}{*}{$\begin{array}{c}\mathrm{pH} \\
\mathrm{H}_{2} \mathrm{O}\end{array}$} & \multirow{2}{*}{$\begin{array}{c}\mathrm{C} \\
\mathrm{g} / \mathrm{kg}\end{array}$} & \multicolumn{8}{|c|}{ Complexo sortivo $\left(\mathrm{cmol}_{\mathrm{c}} / \mathrm{kg}\right)$} & \multirow{2}{*}{$\begin{array}{l}\mathrm{V} \\
\% \\
\end{array}$} & \multirow{2}{*}{$\begin{array}{l}\mathrm{m} \\
\% \\
\end{array}$} & \multicolumn{4}{|c|}{ Ataque sulfúrico $(\mathrm{g} / \mathrm{kg})$} \\
\hline & & & & $\mathrm{Ca}^{2+}$ & $\mathrm{Mg}^{2+}$ & $\mathrm{K}^{+}$ & $\mathrm{Na}^{+}$ & $\mathrm{S}$ & $\mathrm{Al}^{3+}$ & $\mathrm{H}^{+}$ & $\mathrm{T}$ & & & $\mathrm{Si}$ & $\mathrm{Al}$ & $\mathrm{Fe}$ & $\mathrm{Ti}$ \\
\hline \multicolumn{18}{|c|}{ P1 - CAMBISSOLO HÁPLICO Tb Distrófico típico } \\
\hline A & $0-10$ & 4,9 & 14,7 & 1,4 & 0,5 & 0,13 & 0,07 & 2,1 & 0,1 & 4,5 & 6,4 & 33 & 4 & 96 & 98 & 23 & 5,8 \\
\hline AB & $10-44$ & 4,7 & 9,6 & 0,5 & 0,6 & 0,14 & 0,06 & 1,3 & 0,1 & 2,9 & 4,3 & 30 & 7 & 105 & 100 & 25 & 6,4 \\
\hline Bix & 44-115 & 4,9 & 2,0 & 0 , & 7 & 0,08 & 0,07 & 0,8 & 0 & 1,6 & 2,4 & 33 & 0 & 137 & 139 & 37 & 7,7 \\
\hline$C_{1}$ & $115-162$ & 4,6 & 0,9 & 0 & 3 & 0,06 & 0,02 & 0,4 & 0,1 & 1,4 & 1,9 & 21 & 20 & 122 & 124 & 34 & 7,2 \\
\hline $2 C_{2}$ & $162-232$ & 4,5 & 0,7 & 0 & 3 & 0,04 & 0,02 & 0,4 & 0 & 1,3 & 1,7 & 23 & 0 & 115 & 112 & 35 & 7,1 \\
\hline $2 C_{3}$ & $232-250+$ & 4,5 & 0,7 & 0 , & 3 & 0,03 & 0,03 & 0,4 & 0,1 & 1,2 & 1,7 & 23 & 20 & 116 & 111 & 34 & 6,9 \\
\hline \multicolumn{18}{|c|}{ P2 - ARGISSOLO VERMELHO-AMARELO Distrófico típico } \\
\hline Ap & $0-18$ & 5,0 & 7,7 & 0, & 5 & 0,04 & 0,06 & 0,6 & 0,3 & 2,3 & 3,2 & 19 & 33 & 79 & 71 & 17 & 5,2 \\
\hline BAx & $18-35$ & 4,5 & 6,3 & 0 , & 6 & 0,04 & 0,10 & 0,7 & 0,4 & 2,2 & 3,3 & 21 & 36 & 142 & 150 & 25 & 7,8 \\
\hline$B t x_{1}$ & $35-80$ & 4,8 & 3,4 & 0 , & 9 & 0,02 & 0,12 & 1,0 & 0,4 & 1,9 & 3,0 & 33 & 9 & 197 & 200 & 37 & 9,5 \\
\hline $\mathrm{Btx}_{2}$ & $80-115$ & 5,1 & 2,4 & 0 & 8 & 0,02 & 0,14 & 1,0 & 0 & 1,6 & 2,6 & 38 & 0 & 177 & 183 & 37 & 8,7 \\
\hline$C_{1}$ & $115-180$ & 5,2 & 1,3 & 0 & 6 & 0,01 & 0,03 & 0,6 & 0 & 1,0 & 1,6 & 37 & 0 & 152 & 153 & 29 & 7,9 \\
\hline $\mathrm{C}_{2}$ & $180-220+$ & 4,6 & 1,0 & 0 & 4 & 0,01 & 0,02 & 0,4 & 0,1 & 1,2 & 1,7 & 23 & 20 & 126 & 134 & 26 & 6,8 \\
\hline \multicolumn{18}{|c|}{ P3 - ARGISSOLO AMARELO Distrocoeso típico } \\
\hline $\mathbf{A}_{1}$ & $0-7$ & 5,8 & 1,0 & 2,20 & 2,10 & 0,07 & 0,04 & 4,41 & 0,20 & 2,40 & 7,01 & 63 & 4 & - & - & - & - \\
\hline$A_{2}$ & 7-17 & 5,8 & 1,66 & 3,20 & 0,60 & 0,08 & 0,06 & 3,94 & 0,10 & 2,90 & 6,94 & 57 & 2 & - & - & - & - \\
\hline $\mathbf{A}_{3}$ & $17-26$ & 5,8 & 1,20 & 4,80 & 0,70 & 0,09 & 0,09 & 5,68 & 0,10 & 2,50 & 8,28 & 69 & 2 & - & - & - & - \\
\hline $\mathbf{A B x}$ & $26-46$ & 5,5 & 1,00 & 2,30 & 1,30 & 0,08 & 0,08 & 3,76 & 0,10 & 2,50 & 6,36 & 59 & 3 & - & - & - & - \\
\hline Btx 1 & $46-68$ & 5,4 & 0,51 & 1,50 & 0,50 & 0,09 & 0,08 & 2,17 & 0,20 & 1,30 & 3,67 & 59 & 8 & - & - & - & - \\
\hline Btx $_{2}$ & $68-143$ & 5,1 & 0,21 & 0,50 & 1,10 & 0,08 & 0,09 & 1,77 & 0,40 & 1,80 & 3,97 & 45 & 18 & - & - & - & - \\
\hline \multicolumn{18}{|c|}{ P4 - ARGISSOLO AMARELO Distrocoeso abrúptico } \\
\hline $\mathbf{A}_{1}$ & $0-4$ & 5,1 & 33,3 & 3,4 & 1,5 & 0,21 & 0,13 & 5,2 & 0,1 & 7,4 & 12,7 & 41 & 2 & 42 & 37 & 7 & 3,8 \\
\hline$A_{2}$ & $4-15$ & 5,1 & 8,0 & 0 , & 9 & 0,04 & 0,04 & 1,0 & 0,2 & 2,9 & 4,1 & 24 & 17 & 38 & 34 & 7 & 3,8 \\
\hline $\mathbf{A}_{3}$ & $15-30$ & 4,4 & 5,3 & 0 , & 4 & 0,03 & 0,03 & 0,5 & 0,3 & 1,8 & 2,6 & 19 & 37 & 51 & 47 & 9 & 4,6 \\
\hline Btx 1 & $30-100$ & 5,4 & 4,2 & 0 & 9 & 0,03 & 0,07 & 1,0 & 0,1 & 1,5 & 2,6 & 38 & 9 & 107 & 116 & 22 & 7,5 \\
\hline Btx 2 & $100-162$ & 4,8 & 1,7 & 0 & 7 & 0,02 & 0,04 & 0,8 & 0 & 1,5 & 2,3 & 35 & 0 & 116 & 133 & 23 & 8 \\
\hline $\mathrm{C}_{1}$ & $162-185$ & 4,8 & 0,9 & 0 , & 2 & 0,01 & 0,02 & 0,2 & 0,3 & 1,2 & 1,7 & 12 & 60 & 112 & 121 & 23 & 7,3 \\
\hline $\mathrm{C}_{2}$ & $185-215+$ & 4,6 & 1,4 & 0 & 2 & 0,01 & 0,02 & 0,2 & 0,2 & 1,4 & 1,8 & 11 & 50 & 111 & 135 & 28 & 8 \\
\hline
\end{tabular}


Fábio Carvalho Nunes Claudia Csekö Nolasco de Carvalho Geraldo da Silva Vilas Boas Enio Fraga da Silva

Solos vermelhos e amarelos coesos de Tabuleiros Costeiros: gênese, evolução e influência da neotectônica

Álvaro Luiz Mafra Luiz Mafra

José Jackson Andrade Saulo Roberto de Oliveira Vital

Figura 3 - DRX fração argila. $\mathrm{Ca}=$ Caulinta; $\mathrm{H}=$ tratada com hidrazina; $\mathrm{K}=$ tratada com potássio.

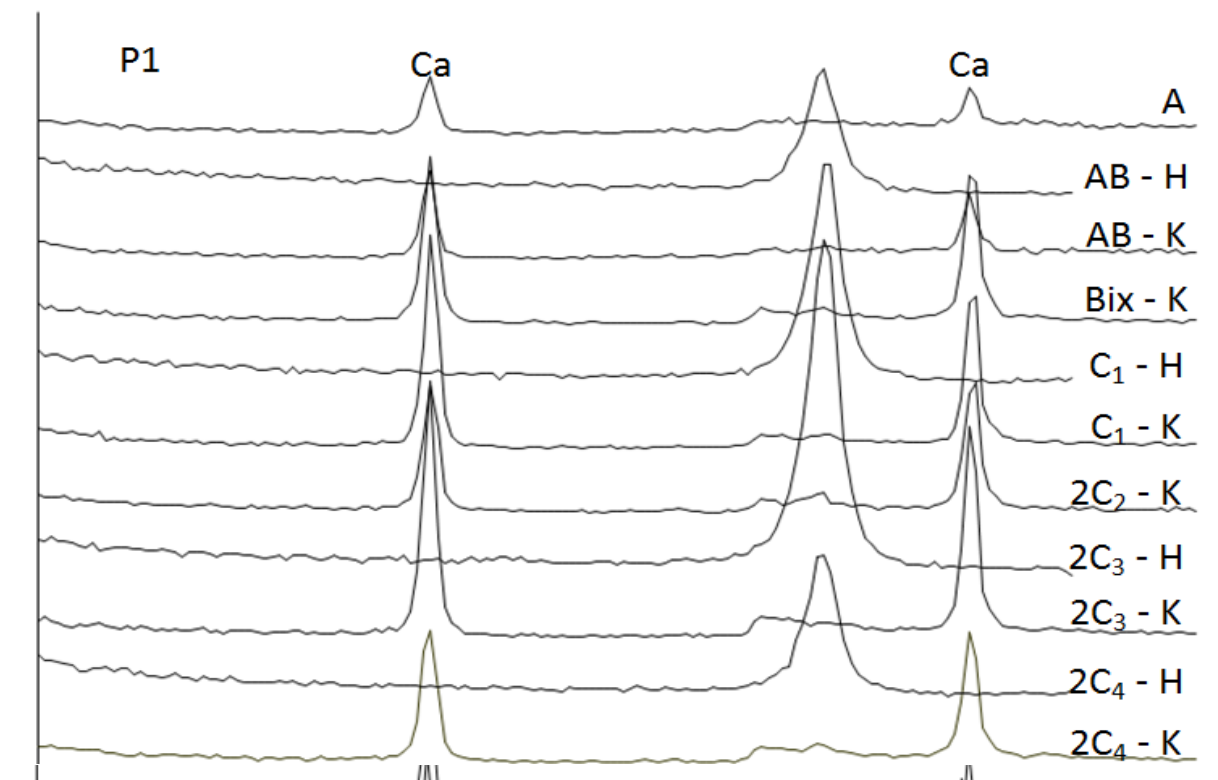

P2
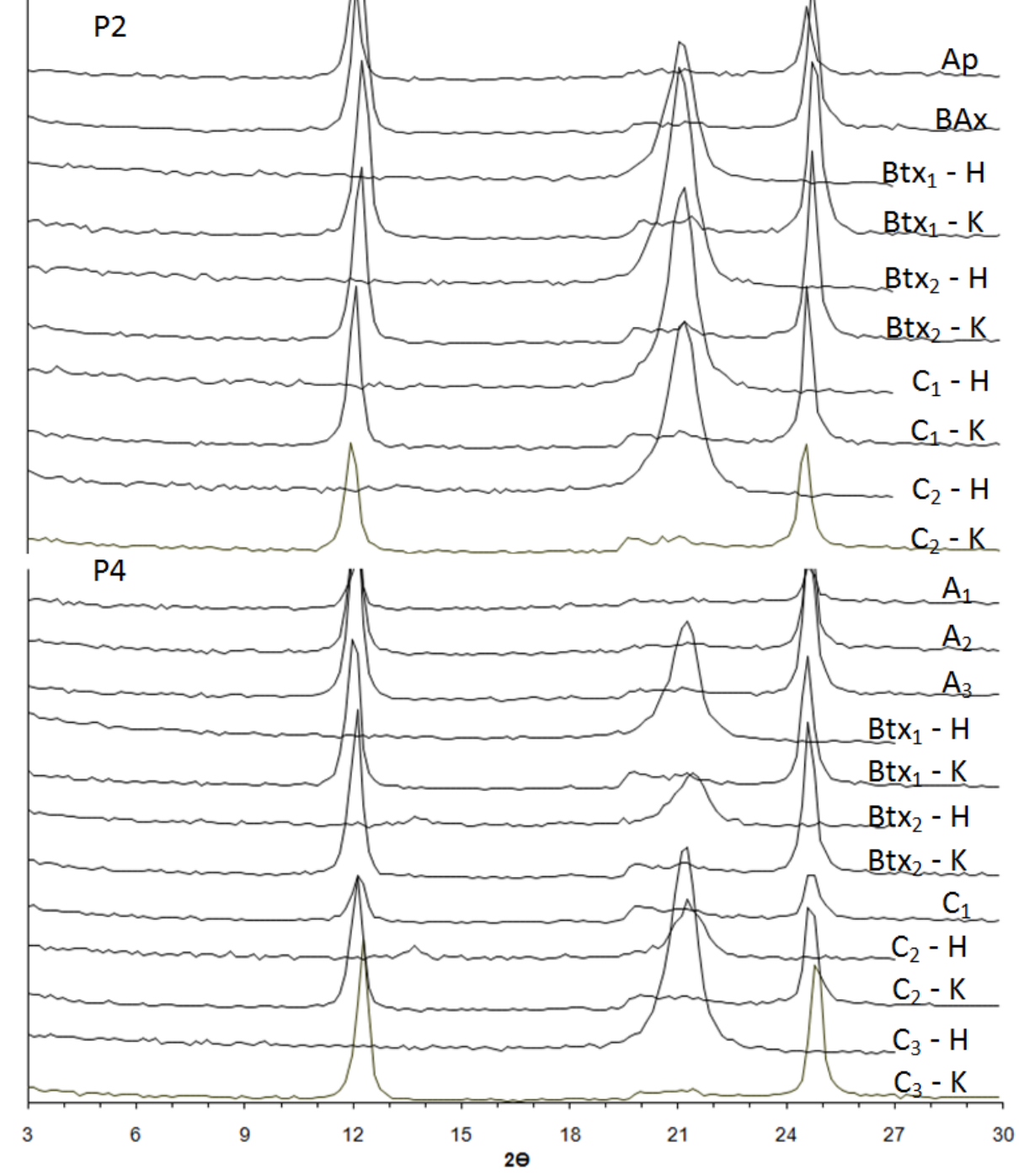
Fábio Carvalho Nunes Claudia Csekö Nolasco de Carvalho Geraldo da Silva Vilas Boas

Enio Fraga da Silva

Solos vermelhos e amarelos coesos de Tabuleiros Álvaro Luiz Mafra Luiz Mafra José Jackson Andrade

Figura 4 - DRX da fração silte.

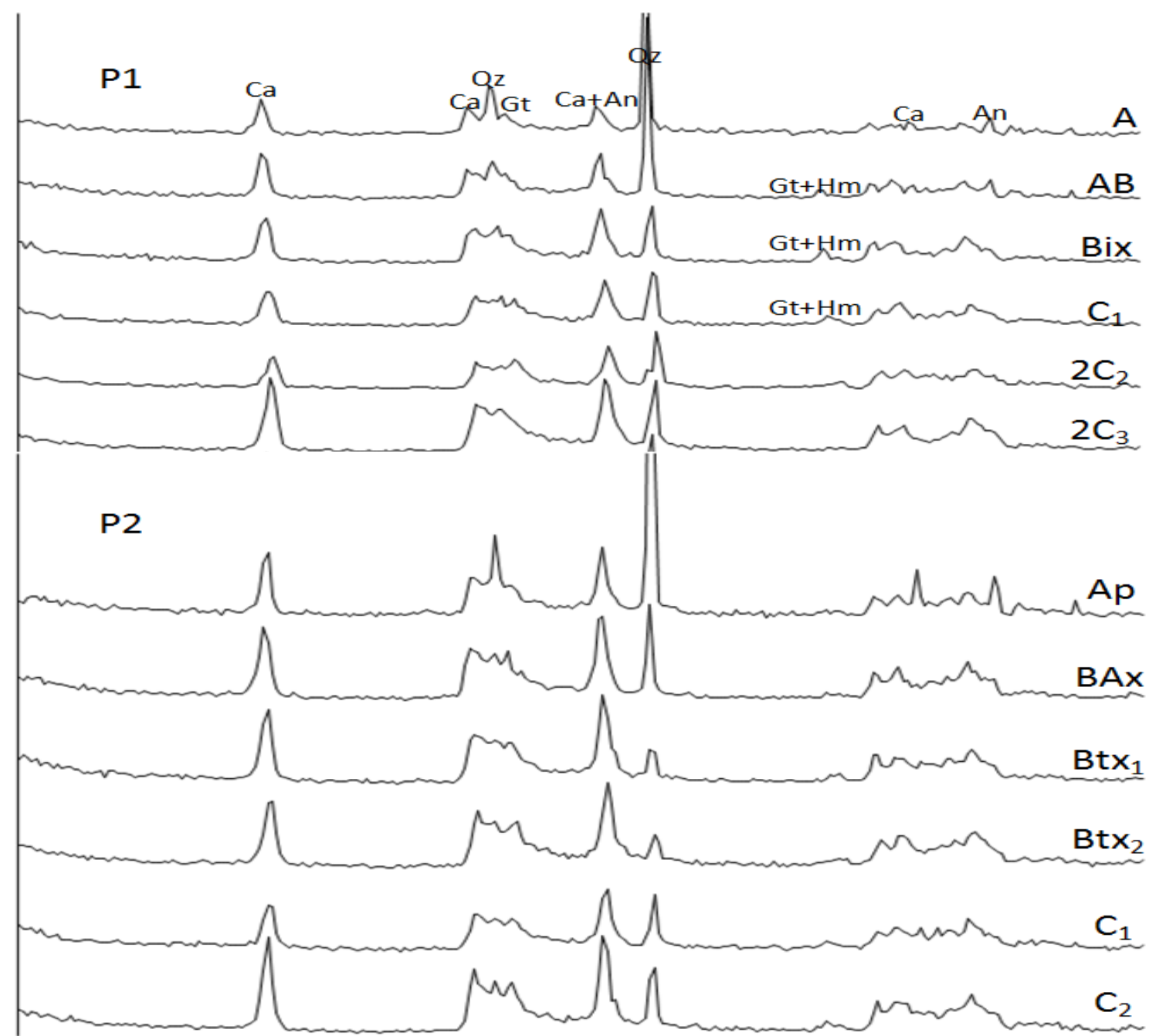

P4
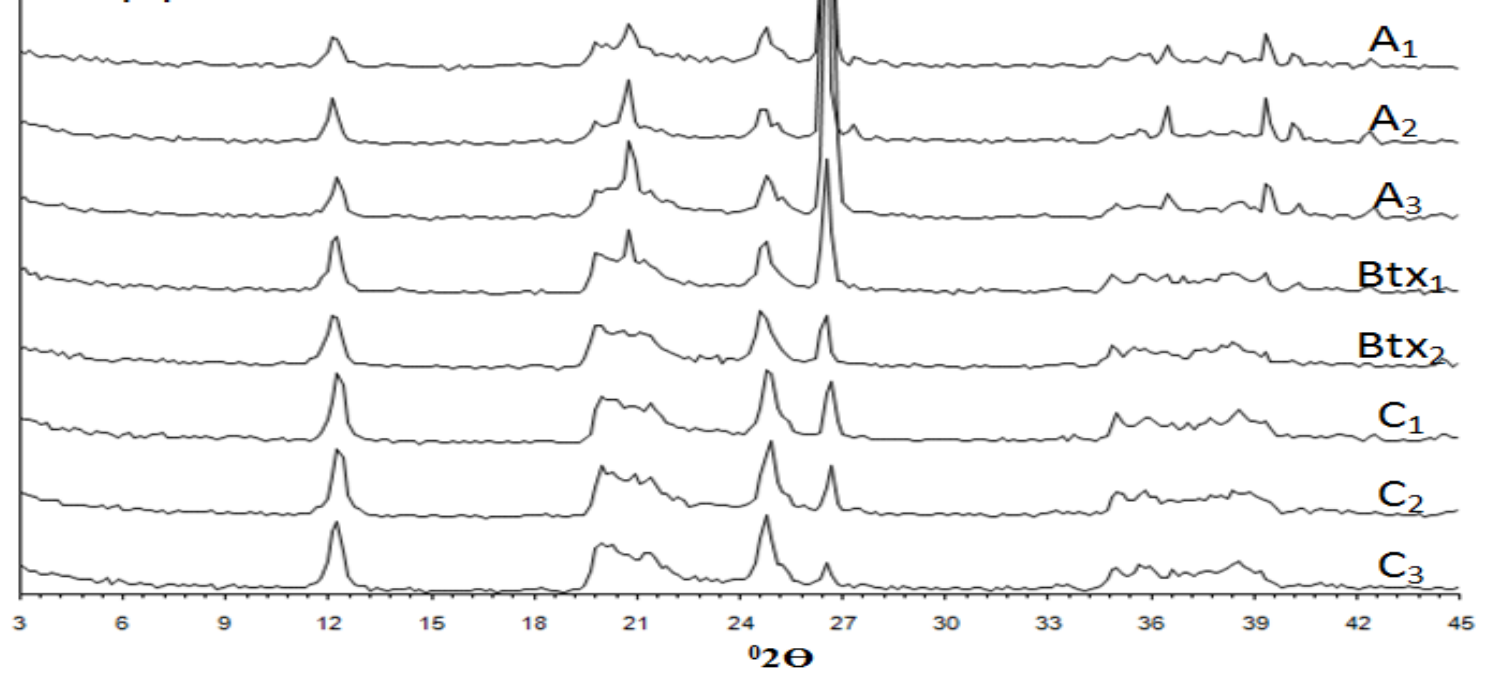
Solos vermelhos e amarelos coesos de Tabuleiros Costeiros: gênese, evolução e influência da neotectônica

Quadro 4 - Principais características micromorfológicas de alguns horizontes dos solos estudados.

\begin{tabular}{|c|c|c|c|c|c|c|}
\hline $\mathbf{H z}$ & Matriz do solo & $\begin{array}{l}\text { Microestrutura de } \\
\text { base }\end{array}$ & Esqueleto & Macroporos & Tipo de macroporo & $\begin{array}{c}\text { Feições } \\
\text { iluviação }\end{array}$ \\
\hline \multicolumn{7}{|c|}{ P1 - CAMBISSOLO HÁPLICO Tb Distrófico típico } \\
\hline A & Isotrópica bruno-avermelhada & QE & $\begin{array}{l}\text { Qz mal selecionado, subarred., nd } \\
\text { p pq degradando }\end{array}$ & $20 \%$ & $\begin{array}{l}\text { Intergranulares complexos } \\
\text { e canais }\end{array}$ & - \\
\hline$A B$ & $\begin{array}{l}\text { Isotrópica bruno-avermelhada, com pequenos } \\
\text { domínios anisotrópicos intra-agregados }\end{array}$ & Q Pa & $\begin{array}{l}\text { Qz mal selecionado, subarred., nd } \\
\text { p pq degradando }\end{array}$ & $20 \%$ & $\begin{array}{l}\text { Intergranulares complexos } \\
\text { e canais }\end{array}$ & - \\
\hline Bix & $\begin{array}{l}\text { Isotrópica vermelho-amarelada, com domínios } \\
\text { anisotrópicos intra-agregados }\end{array}$ & $\mathrm{Pa} Q \mathrm{Pf}$ & $\begin{array}{l}\text { Qz mal selecionado, subarred., nd } \\
\text { p pq md degradando }\end{array}$ & $27 \%$ & $\begin{array}{l}\text { Intergranulares complexos } \\
\text { e cavidades }\end{array}$ & - \\
\hline $\mathrm{C}_{1}$ & $\begin{array}{l}\text { Isotrópica vermelha e amarela, com forte } \\
\text { anisotropia em alguns setores }\end{array}$ & $\mathrm{Pa} P f \mathrm{E}$ & $\begin{array}{l}\text { Qz mal selecionado, subarred., nd } \\
\text { c pq md degradando }\end{array}$ & $30 \%$ & Intergranulares complexos & - \\
\hline $2 \mathrm{C}_{2}$ & $\begin{array}{l}\text { Isotrópica vermelha e amarela, com forte } \\
\text { anisotropia em alguns setores }\end{array}$ & $\mathrm{Pa} \mathrm{Q}$ & $\begin{array}{l}\text { Qz mal selecionado, subarred. e } \\
\text { arred., nd p pq degradando, mi } \\
\text { P2 - ARGISSOLO VERMELHO-AM }\end{array}$ & $\begin{array}{l}36 \% \\
\text { ARELO Distrófic }\end{array}$ & $\begin{array}{l}\text { Intergranulares complexos } \\
\text { e canais } \\
\text { típico }\end{array}$ & - \\
\hline Ap & Isotrópica amarelo-avermelhado & $\mathrm{Pa}$ & Qz mal selecionado subarred. & $35 \%$ & $\begin{array}{l}\text { Intergranulares } \\
\text { complexos, simples e } \\
\text { canais }\end{array}$ & - \\
\hline$B t_{1}$ & $\begin{array}{l}\text { Isotrópica vermelho-amarelada, com domínios } \\
\text { anisotrópicos intra-agregados }\end{array}$ & $\mathrm{Pa}$ & $\begin{array}{l}\text { Qz mal selecionado subarred., nd } \\
\text { p pq }\end{array}$ & & $\begin{array}{l}\text { Intergranulares complexos } \\
\text { e cavidades }\end{array}$ & $\begin{array}{l}\text { Cutãs e quasi-cutãs } \\
\text { de argila e ferro }\end{array}$ \\
\hline $\mathrm{C}_{1}$ & $\begin{array}{l}\text { Isotrópica vermelha e amarela, com forte } \\
\text { anisotropia em alguns setores }\end{array}$ & Ple Pe PfE & $\begin{array}{l}\text { Qz mal selecionado subarred., nd } \\
\text { c pq md degradando } \\
\text { P3 - ARGISSOLO AMARELC }\end{array}$ & $\begin{array}{l}30 \% \\
\text { Distrocoeso típ }\end{array}$ & $\begin{array}{l}\text { Intergranulares complexos } \\
\text { e cavidades }\end{array}$ & \\
\hline$A_{3}$ & $\begin{array}{l}\text { Isotrópica amarronzada, com pequenos domínios } \\
\text { anisotrópicos intra-agregados }\end{array}$ & Q G & Qz mal selecionado subarred & $20 \%$ & $\begin{array}{l}\text { Intergranulares } \\
\text { complexos, simples e } \\
\text { canais }\end{array}$ & $\begin{array}{l}\text { Ferrãs e possíveis } \\
\text { silicãs }\end{array}$ \\
\hline$A B x$ & $\begin{array}{l}\text { Isotrópica amarronzada, com pequenos domínios } \\
\text { anisotrópicos intra-agregados }\end{array}$ & Q G & Qz mal selecionado subarred & $15 \%$ & $\begin{array}{l}\text { Intergranulares complexos } \\
\text { e canais }\end{array}$ & $\begin{array}{l}\text { Ferrãs e possíveis } \\
\text { silicãs }\end{array}$ \\
\hline$B x_{1}$ & $\begin{array}{l}\text { Isotrópica amarronzada, com domínios } \\
\text { anisotrópicos intra-agregados }\end{array}$ & $\mathrm{Pe}$ & Qz mal selecionado subarred & $25 \%$ & \multirow{3}{*}{$\begin{array}{l}\text { Intergranulares complexos } \\
\text { e cavidades } \\
\text { Intergranulares complexos } \\
\text { e cavidades } \\
\text { Intergranulares complexos } \\
\text { e cavidades } \\
\text { ico }\end{array}$} & \multirow[t]{3}{*}{$\begin{array}{l}\text { Argilãs e possíveis } \\
\text { silicãs }\end{array}$} \\
\hline $\mathrm{Btx} \mathrm{x}_{2}$ & $\begin{array}{l}\text { Isotrópica amarelada, com domínios } \\
\text { anisotrópicos intra-agregados }\end{array}$ & $\mathrm{Pe}$ & $\begin{array}{l}\text { Qz mal selecionado subarred., nd } \\
\text { p pq }\end{array}$ & $40 \%$ & & \\
\hline$C_{1}$ & $\begin{array}{l}\text { Isotrópica avermelhada, com forte anisotropia em } \\
\text { alguns setores }\end{array}$ & Ple Pe & \multicolumn{2}{|c|}{$\begin{array}{l}\text { angul., nd c pq md degradando } \\
\text { P4 - ARGISSOLO AMARELO Distrocoeso abrúptico }\end{array}$} & & \\
\hline$B t x_{1}$ & $\begin{array}{l}\text { Isotrópica avermelhada, com domínios } \\
\text { anisotrópicos intra-agregados }\end{array}$ & $\mathrm{Pe}$ & Qz mal selecionado subarred. & $45 \%$ & $\begin{array}{l}\text { Intergranulares complexos } \\
\text { e cavidades }\end{array}$ & Ferrãs e argilãs \\
\hline $\mathrm{C}_{1}$ & $\begin{array}{l}\text { Isotrópica avermelhada, com forte anisotropia em } \\
\text { alguns setores }\end{array}$ & $\mathrm{Ple} \mathrm{Pe}$ & $\begin{array}{l}\text { Qz mal selecionado arred. e } \\
\text { angul., nd p pq degradando }\end{array}$ & $30 \%$ & $\begin{array}{l}\text { Intergranulares complexos } \\
\text { e cavidades }\end{array}$ & - \\
\hline
\end{tabular}


Fábio Carvalho Nunes

Claudia Csekö Nolasco de Carvalho

Geraldo da Silva Vilas Boas

Enio Fraga da Silva

Solos vermelhos e amarelos coesos de Tabuleiros Costeiros: gênese, evolução e influência da neotectônica

Álvaro Luiz Mafra Luiz Mafra

José Jackson Andrade

Saulo Roberto de Oliveira Vital

Figura 5 - Fotomicrografias em microscópio petrográfico e eletrônico de varredura. Em $A, B, C$ e D a matriz nodular está se degradando dando origem a um plasma vermelho escuro (PE) e amarelo-avermelhado (PC). Em E observam-

se predominantemente caulinitas arredondadas pequenas e em $\mathrm{F}$ as zonas mais brilhantes (1 e 2) indicam

concentração mais acentuada dos compostos ferruginosos, contudo sem individualização visível de hematita ou

goethita. Em G revestimento de sílica sem definição de forma no horizonte Bi e em $\mathrm{H}$ detalhe de setores de $\mathrm{A}$ com aumento de 5.500X. Qz = Quartzo, V = Vazio e P = Plasma.
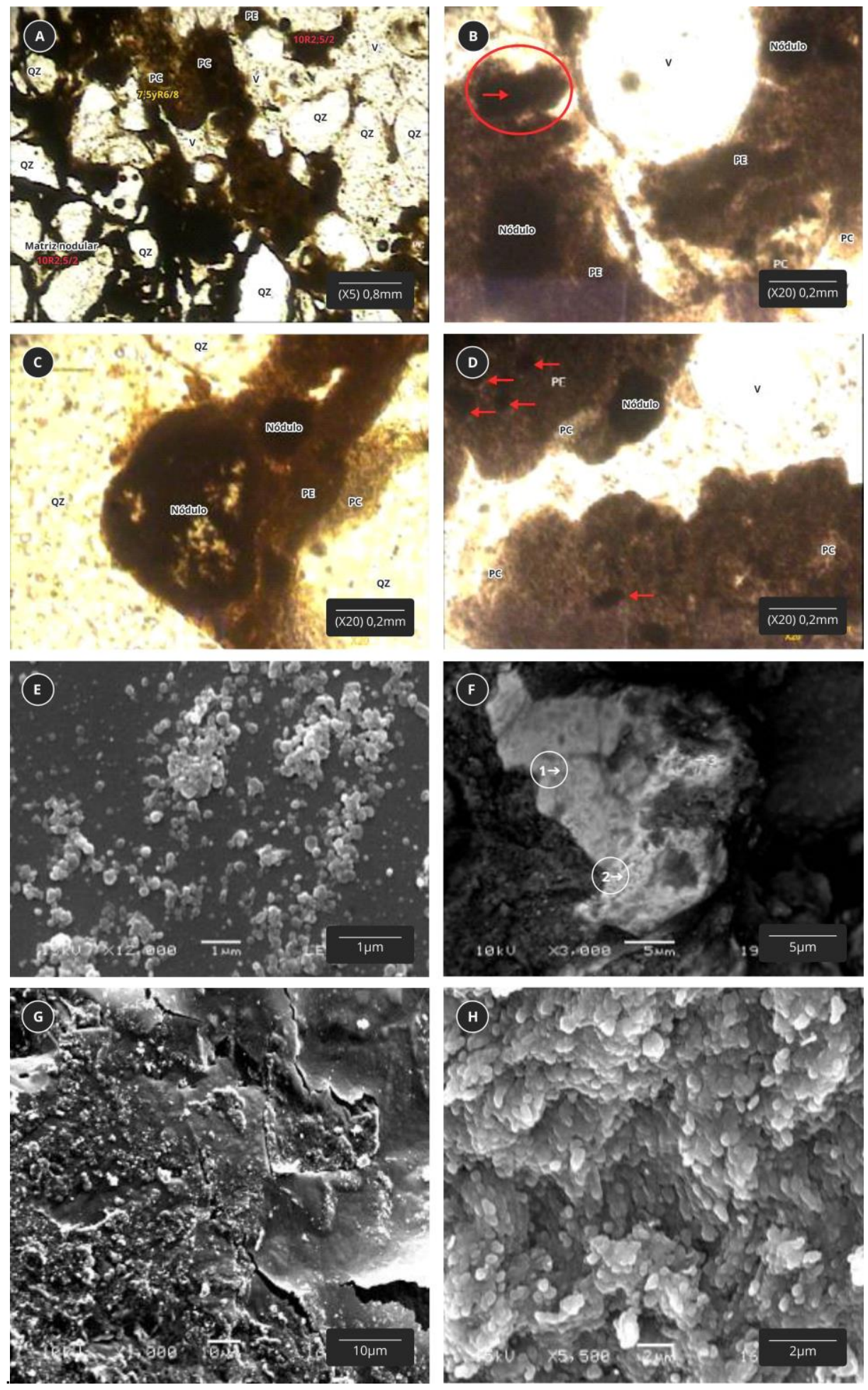


\section{Perfil P2}

O horizonte C1 possui contextura porfírica ligeiramente espaçada, porfírica espaçada, porfírica fechada e enáulica, com esqueleto constituído por grãos de quartzo mal selecionados, subarredondados, alguns arredondados e angulosos. Localmente podem ser notados nódulos ferruginosos em diferentes estádios de alteração, originando um plasma vermelho e amarelo (Figura 6AB). Nos horizontes Btx1 e Btx2 a contextura é porfírica aberta, o esqueleto possui grãos de quartzo mal selecionados subarredondados e nódulos amarelos e vermelhos. São observadas feições que lembram cutãs e quasi-cutãs de argila e de ferro.

No horizonte BAx a microestrutura é porfírica aberta, com esqueleto constituído de grãos de quartzo mal selecionados subarredondados, enquanto que no horizonte A é quitônica e setores enáulica, com esqueleto de grãos de quartzo mal selecionados e subarredondados.

Os materiais estudados ao MEV dos horizontes Btx1, Btx2 (Figura 6CDEF) mostram as seguintes características: argilas constituídas por caulinitas arredondadas pequenas (entre $1 \mu$ e $0,2 \mu$ ), ocorrendo também frações menores que $0,2 \mu$ e maiores que $1 \mu$; compostos de sílica mal-cristalizada revestindo o esqueleto e o plasma de algumas amostras. Na Figura 6E pode-se observar a superfície do grão de quartzo com feições pontiagudas (serrilhadas), indicando neoformação do material. As características morfológicas dessas feições, aliadas a observações que sinalizam dissolução de materiais dos horizontes superficiais do solo, indicam que se trata de um polimorfo da sílica. Os compostos de ferro não foram identificados em sua forma individualizada, notando-se apenas zonas mais enriquecidas com ferro.

\section{Perfil P3}

Nos horizontes C2 e C1 a contextura é porfírica ligeiramente espaçada e porfírica espaçada, enquanto que no Btx2 a microestrutura é porfírica espaçada. Os esqueletos dos horizontes C2 e C1 são constituídos por grãos de quartzo mal selecionados arredondados e angulosos e nódulos ferruginosos vermelhoescuros, enquanto que o Btx2 ocorre grãos de quartzo mal selecionados subarredondados. No horizonte Btx1 a contextura é gefúrica, no $A B x$ é quitônica e nos demais horizontes ( $A 1, A 2$ e $A 3)$ é gefúrica. Nos referidos horizontes pode-se observar cutãs de iluviação, provavelmente silicãs e ferrãs compondo o fundo matricial (Figura 7AB), em alguns casos estão relacionados a fendas da pedofábrica.

Os horizontes coesos desse setor foram analisados utilizando o MEV, os quais apresentam: argilas constituídas por caulinitas arredondadas; zonas com revestimentos argilosos em torno de canais e superfícies lisas que sugerem possíveis cutãs (Figura 7D); zonas esbranquiçadas associadas a possíveis cutãs (Figura 7E), mas sem individualização de cristais de caulinita em aumentos de 350X e 500X. Com aumento de 2.000X começam a aparecer algumas pontuações com formato arredondado e com aumentos de 15.000X notam-se caulinitas arredondadas pequenas e muito pequenas, bem como zonas com revestimentos esbranquiçados que sugerem compostos silico-aluminosos ou alumino-silicosos malcristalizados (Figura 7F). Não foram identificados cristais individualizados de goethita e hematita.

\section{Perfil P4}

Nos horizontes C2 e C1 a contextura é porfírica ligeiramente espaçada e porfírica espaçada, enquanto que no Btx2 e Btx1 é porfírica espaçada. Os esqueletos dos horizontes C2 e C1 são constituídos por grãos de quartzo mal selecionados arredondados e angulosos, possuindo alguns nódulos ferruginosos vermelho-escuros (Figura 7C), enquanto que no Btx2 e Btx1 ocorrem grãos de quartzo mal selecionados subarredondados, argilãs e ferrãs.

Nos horizontes A1, A2 e A3 a contextura é gefúrica, com esqueleto com esqueleto de grãos de quartzo mal selecionados e subarredondados.

\begin{tabular}{|c|c|c|c|c|}
\hline Caminhos de Geografia & Uberlândia & v. 20, n. 72 & Dez/2019 & Página 306 \\
\hline
\end{tabular}


Fábio Carvalho Nunes

Claudia Csekö Nolasco de Carvalho Geraldo da Silva Vilas Boas

Enio Fraga da Silva

Solos vermelhos e amarelos coesos de Tabuleiros

Costeiros: gênese, evolução e influência da neotectônica

Álvaro Luiz Mafra Luiz Mafra

José Jackson Andrade

Saulo Roberto de Oliveira Vital

Figura 6 - Fotomicrografias do horizonte C2 do perfil 2. Em A e B nódulos em estádios diferentes de degradação, originando manchas vermelhas (Mv) e amarelas (Ma). Em C caulinitas arredondadas pequenas, com setores recobertos (ver setas) por compostos silico-aluminosos ou alumino-silicosos malcristalizados. Em $D$ zonas mais brilhantes enriquecidas com ferro, mas sem individualização de cristais de

hematita ou goethita. Em E superfície do grão de quartzo com feições pontiagudas e em $F(1$ e 2$)$ revestimentos de compostos silicosos sobre grãos de quartzo. Qz - quartzo; V - vazio.
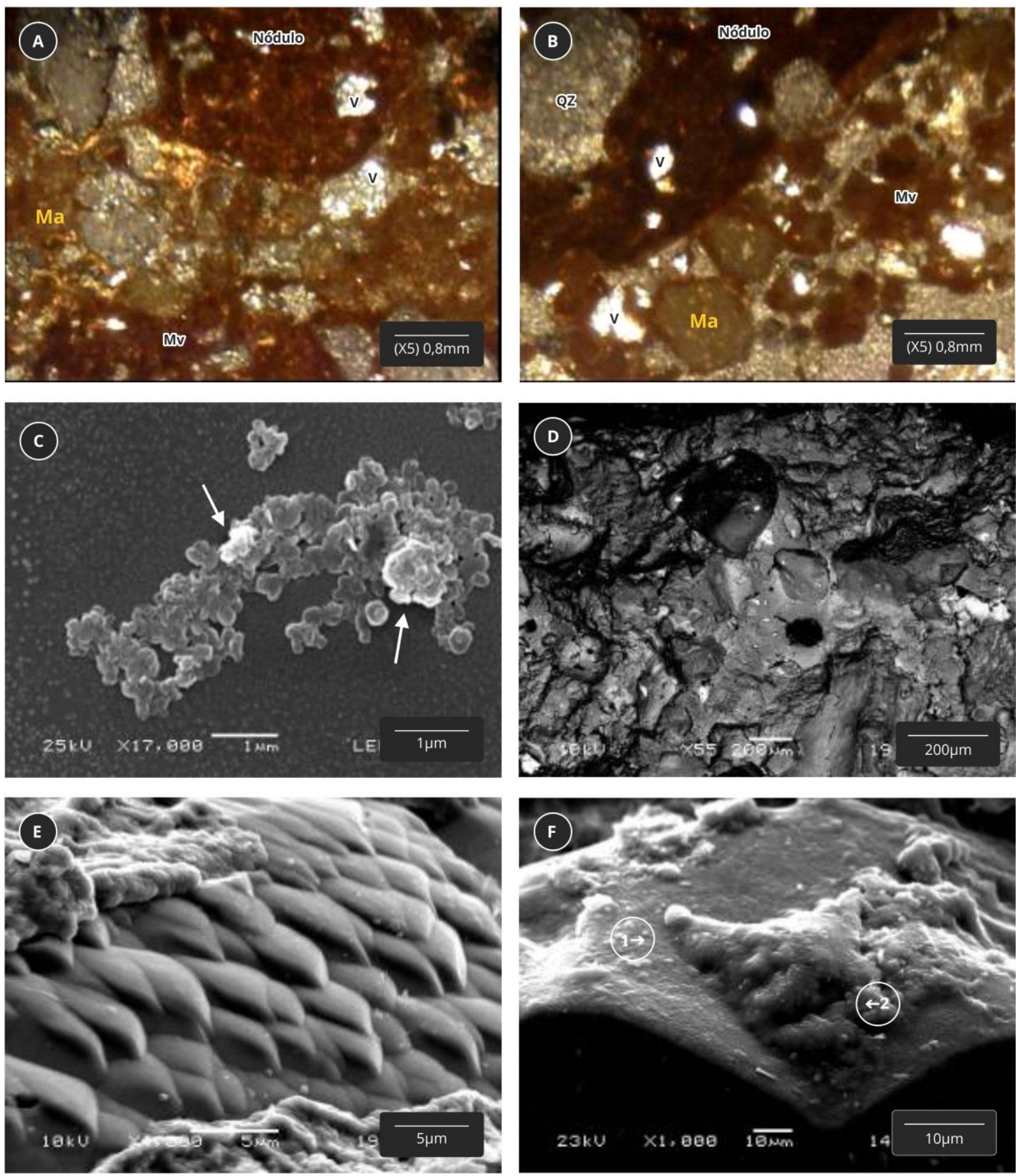
Fábio Carvalho Nunes

Claudia Csekö Nolasco de Carvalho Geraldo da Silva Vilas Boas

Enio Fraga da Silva

Solos vermelhos e amarelos coesos de Tabuleiros

Costeiros: gênese, evolução e influência da neotectônica

Álvaro Luiz Mafra Luiz Mafra

José Jackson Andrade

Figura 7 - Em A e B silicãs e ferrãs recobrindo grãos de quartzo e preenchendo fraturas no horizonte Btx1 do perfil 3. Em $\mathrm{C}$ nódulos reliquiares no horizonte $\mathrm{C} 2$ do perfil 4. Em D zonas com revestimentos argilosos em torno de canais e superfícies lisas que sugerem possíveis cutãs no horizonte Btx1 do perfil 3 e em $\mathrm{E}$ zonas esbranquiçadas associadas a possíveis cutãs, mas sem individualização de cristais de caulinita no horizonte Btx1 do perfil 3. Em F caulinitas arredondadas pequenas e zonas com revestimentos esbranquiçados que sugerem compostos silicosos ou alumino-silicosos mal-cristalizados no horizonte Btx1 do perfil 3.
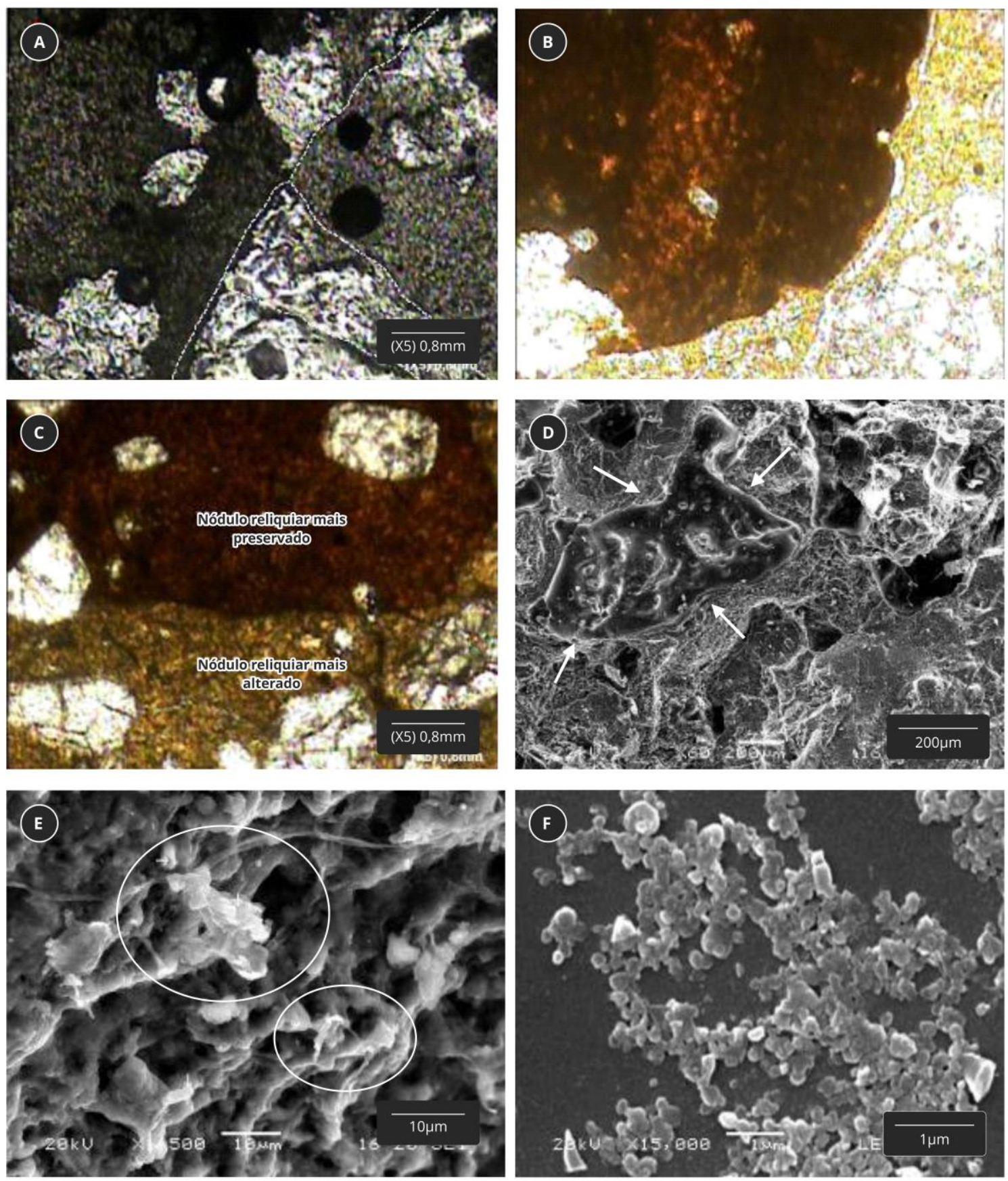
Fábio Carvalho Nunes

Claudia Csekö Nolasco de Carvalho

Geraldo da Silva Vilas Boas

Enio Fraga da Silva

Solos vermelhos e amarelos coesos de Tabuleiros

Álvaro Luiz Mafra Luiz Mafra

José Jackson Andrade

Costeiros: gênese, evolução e influência da neotectônica

Saulo Roberto de Oliveira Vital

\section{GÊNESE E EVOLUÇÃO DA COBERTURA}

Os perfis apresentam cores variáveis, a depender da profundidade do solum e da posição que assumem na paisagem. Predominam cores brunadas e amareladas nos horizontes superficiais, enquanto que cores mais avermelhadas se pronunciam com acréscimo da profundidade e em direção à encosta da vertente. As variações do matiz, valor e croma estão relacionados ao tipo de óxido de ferro presente, o que conduz à reflexão das condições ambientais que determinaram a sua formação e à presença da matéria orgânica (KAMPF e SCHWERTMANN, 1983). As cores amarelas são atribuídas à presença da goethita e as cores vermelhas à hematita, podendo coexistirem em solos vermelhos (KAMPF e CURI, 2003). A goethita é mais estável em ambientes úmidos, enquanto que, a hematita é instável. Alguns autores associam a presença da hematita em ambientes úmidos a um relicto de paleoclima seco (SCHWERTMANN, 1971; ALMEIDA et al., 2000), pois os solos vermelhos são instáveis em ambientes quentes e úmidos devido à degradação preferencial da hematita, por isso as mesmas na área estudada foram interpretadas como relíquias de um paleoclima mais seco.

Os solos vermelhos teriam se formado em condições climáticas mais secas, a partir da intemperização de arenitos lamosos conglomeráticos ferruginosos e de arenitos lamosos do Grupo Barreiras, sendo que o material de origem pré-intemperizado e pobre em minerais ferromagnesianos possibilitou o desenvolvimento de uma cobertura ferralítica. Ribeiro (1982) estudando solos vermelhos em Jequié, semiárido da Bahia, explica que os solos estão sofrendo atualmente um processo de ferralitização, indicando que este processo pedogenético não está restrito a ambientes úmidos.

O avanço da pedogênese ferralítica dos solos vermelhos foi acompanhado pela conformação de horizontes coesos, a qual pode ter sido favorecida pelo material de origem (arenito lamoso conglomerático ferruginoso), de contextura inicialmente porfírica fechada (close porphyric) e porfírica ligeiramente espaçada (single spacedporphyric), que ao se intemperizar deixou microporos que foram aos poucos preenchidos por caulinitas pequenas (entre $1 \mu$ e $0,2 \mu$ ), transformando-se em contextura porfírica espaçada (double spacedporphyric) e porfírica aberta (open porphyric), conforme conceitos de Stoops (2003). As microporosidades deixadas pela lenta intemperização do material de origem servem como uma rede que intercepta os finos iluviados, mantendo o adensamento próximo ao da matriz inicial, mas agora com uma porosidade funcional. Uma pequena iluviação de materiais argilosos foi suficiente para originar o horizonte coeso.

Com a mudança do clima para uma condição mais úmida, os solos vermelhos teriam se desestabilizado, começando a ocorrer uma progressiva xantização (amarelecimento) da cobertura pedológica devido à degradação preferencial da hematita, favorecida pela formação de horizontes coesos que dificultaram a drenagem vertical e criaram condições moderadas de redução ou de "falsa hidromorfia" (FRISTCH et al. 1997) e, por consequência, redução do ferro, liberação de íons de $\mathrm{Fe}^{+2}$ e acidificação dos materiais argilosos, fenômeno este denominado de ferrólise (Brinkman, 1979).

A tendência natural dos solos vermelhos em ambientes úmidos é a progressiva xantização, o que ocorre a partir dos horizontes superficiais devido a um efeito combinado da atividade da água e da matériaorgânica (BEAUVAIS e TARDY, 1991). A intensa mineralização da matéria-orgânica consome oxigênio e libera gás-carbônico e água para o meio, conforme a reação $\mathrm{CH}_{2} \mathrm{O}+\mathrm{O}_{2} \square \mathrm{CO}_{2}+\mathrm{H}_{2} \mathrm{O}$. A oxidação da matéria-orgânica provoca redução do ferro, dissolvendo a hematita $\left(\mathrm{Fe}_{2} \mathrm{O}_{3}+0,5 \mathrm{CH}_{2} \mathrm{O}+4 \mathrm{H}^{+} \square 2 \mathrm{Fe}^{2+}+\right.$ $0,5 \mathrm{CO}_{2}+2,5 \mathrm{H}_{2} \mathrm{O}$ ) e, como a goethita é o mineral secundário de ferro mais estável, desde que o ambiente não seja permanentemente saturado, o ferro liberado pela dissolução da hematita tende a se reprecipitar em forma de goethita, conforme a reação: $\mathrm{Fe}^{2+}+\mathrm{H}_{2} \mathrm{O} \square \mathrm{Fe}^{3}+\mathrm{O}(\mathrm{OH})+\mathrm{e}^{-}$. Entretanto, a xantização dos solos vermelhos em ambientes úmidos também pode ocorrer devido à manutenção residual da goethita (DUARTE et al., 2000).

A instalação do clima mais úmido também teria provocado à dissecação do relevo, originando uma superfície convexa com drenagens diferenciadas ao longo da vertente, favorecendo o avanço da xantização de solos de topo e manutenção de solos avermelhados e vermelhos da ombreira em direção à encosta. Isto ocorreu porque o topo começou a funcionar como ambiente de saturação temporária de água, enquanto que na ombreira e na encosta a drenagem superficial mais eficiente criou condições

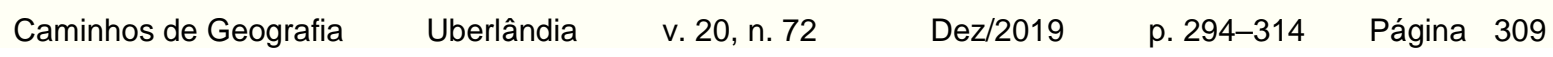


Fábio Carvalho Nunes

Claudia Csekö Nolasco de Carvalho

Geraldo da Silva Vilas Boas

Enio Fraga da Silva

Solos vermelhos e amarelos coesos de Tabuleiros

Álvaro Luiz Mafra Luiz Mafra

José Jackson Andrade

Costeiros: gênese, evolução e influência da neotectônica

Saulo Roberto de Oliveira Vital

oxidantes, favorecendo a manutenção temporária de solos vermelhos, temporária porque os solos vermelhos estão em desequilíbrio com as condições pedobioclimáticas reinantes.

Os horizontes coesos se tornaram mais endurecidos e espessos quando a cobertura evoluiu para amarela, devido: à diminuição dos teores de ferro livre; avanço da argiluviação, notadamente de caulinitas pequenas; degradação do plasma argiloso dos horizontes superficiais e precipitação em subsuperfície de materiais silico-aluminosos ou alumino-silicosos; a natureza do material precipitado precisa ser mais bem estudada. O solo constituído de caulinitas pequenas associado ao comportamento da argila dispersa sugere uma maior probabilidade de translocação de partículas argilosas, entre ou dentro do mesmo horizonte, aumentando a superfície de contato entre os constituintes do solo e promovendo expressivo ganho de resistência, isto porque os pontos de contato são mais numerosos, o que permite maior número de vínculos cimentantes (LAMOTTE et al., 1997a; 1997b; CORRÊA et al., 2008). Segundo Lamotte et al. (1997a) e Corrêa et al. (2008), um pequeno aumento no teor de argila muito fina é o que pode promover a ocorrência de horizontes endurecidos em solos, contudo no presente trabalho não foi confirmada a hipótese. Necessitam-se, no entanto, estudos quantitativos e com outras técnicas para maiores esclarecimentos.

É importante destacar que o P3 é o perfil que apresenta horizontes superficiais mais arenizados, com maior disjunção plasma-esqueleto e degradação do plasma argiloso, bem como horizontes adensados mais duros e espessos, que chega a perfazer mais de $140 \mathrm{~cm}$ de profundidade, isto porque está situado em uma pequena depressão (depressão fechada). Tais informações corroboram com a hipótese de que a gênese dos horizontes coesos tem como contributo os materiais iluviados dos horizontes superficiais. Além disso, nota-se que o perfil P3 está passando por um processo de "micropodzolização". Stutzer (1998) explica que o processo de podzolização começa pelo desenvolvimento progressivo de horizontes superficiais arenosos, devido ao acúmulo de matéria-orgânica do tipo MOR associado a pH ácido. Em solos tropicais com hidromorfia e pobres em nutrientes, a humificação da matéria-orgânica é muito lenta (BUURMAN e JONGMANS, 2005), decorrendo daí uma mineralização muito incompleta que libera, sobretudo, ácidos fúlvicos, os quais favorecem a degradação dos materiais argilosos (RIBEIRO, 1998).

Os estudos realizados por Carvalho (2001) e Fortunato (2004) mostram que sistemas de falhas ou fraturas proporcionam a formação de fraturas ou fendas na cobertura pedológica, controlando, por conseguinte, a formação e distribuição de depressões fechadas, as quais funcionam como polos incializadores dos processos de podzolização. A interpretação de fotografias aéreas da área de estudo mostra que as depressões fechadas, inclusive a do perfil P3, e os espodossolos ocorrem no entrecruzamento de falhas, aproximadamente nos sentidos NE-SW, NW-SE, E-W e N-S (Figura 8), coincidindo com as anisotropias regionais oriundas de reativações tectônicas que ocorrem a partir do Plioceno (SAADI, 1993; BEZERRA, 1998) e afetaram o Grupo Barreiras e seus solos (FORTUNATO, 2004).

Os pontos de cruzamento determinariam fluxos preferenciais de drenagem, interferindo na dinâmica da água, implicando em exportação de material, abatimento da superfície e estabelecimento de condições hidromórficas, como sugerido por Filizola e Boulet (1996), Carvalho (2001) e Fortunato (2004). A redução do fluxo de escoamento superficial é imposta pela nova condição de relevo e acentuada pela presença de horizontes coesos que diminuem a velocidade de infiltração. Segundo Rossetti e Dominguez (2012), existem muitas evidências que apontam para a importância das reativações tectônicas pós-deposição do Grupo Barreiras, especialmente as de natureza geomorfológica e, certamente, as depressões fechadas e os processos de podzolização desencadeados na área também evidenciam a influência da neotectônica.

Além dos aspectos supracitados, as análises micromorfológicas do P3 revelam a existência de fendas na pedofábrica, indicando também a relação com o sistema de falhas ou fraturas que formaram a pequena depressão fechada, a qual parece evoluir de forma centrífuga arenizando progressivamente as bordas da depressão. Isto ocorre porque a depressão proporciona o acúmulo de águas nos períodos pluviosos e provoca a formação de um ambiente redutor temporário, que associado à presença de uma matéria orgânica ácida e rica em ácidos fúlvicos livres e a processos como a ferrólise, degrada o plasma argiloso dos solos e libera materiais que contribuem para a evolução da coesão. O processo de "micropodzolição" identificado revela, certamente, os estágios iniciais dos grandes processos de podzolização e evolução da paisagem estudados por Fortunato (2004) e Costa Júnior (2008) no Litoral Norte da Bahia.

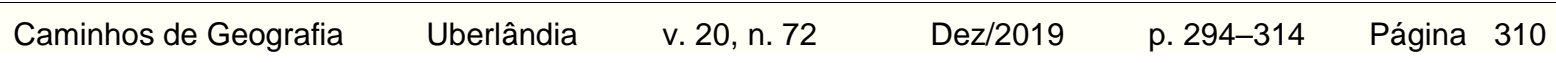


Figura 8 - Lineamentos estruturais prováveis e relação com os solos da área de estudo.

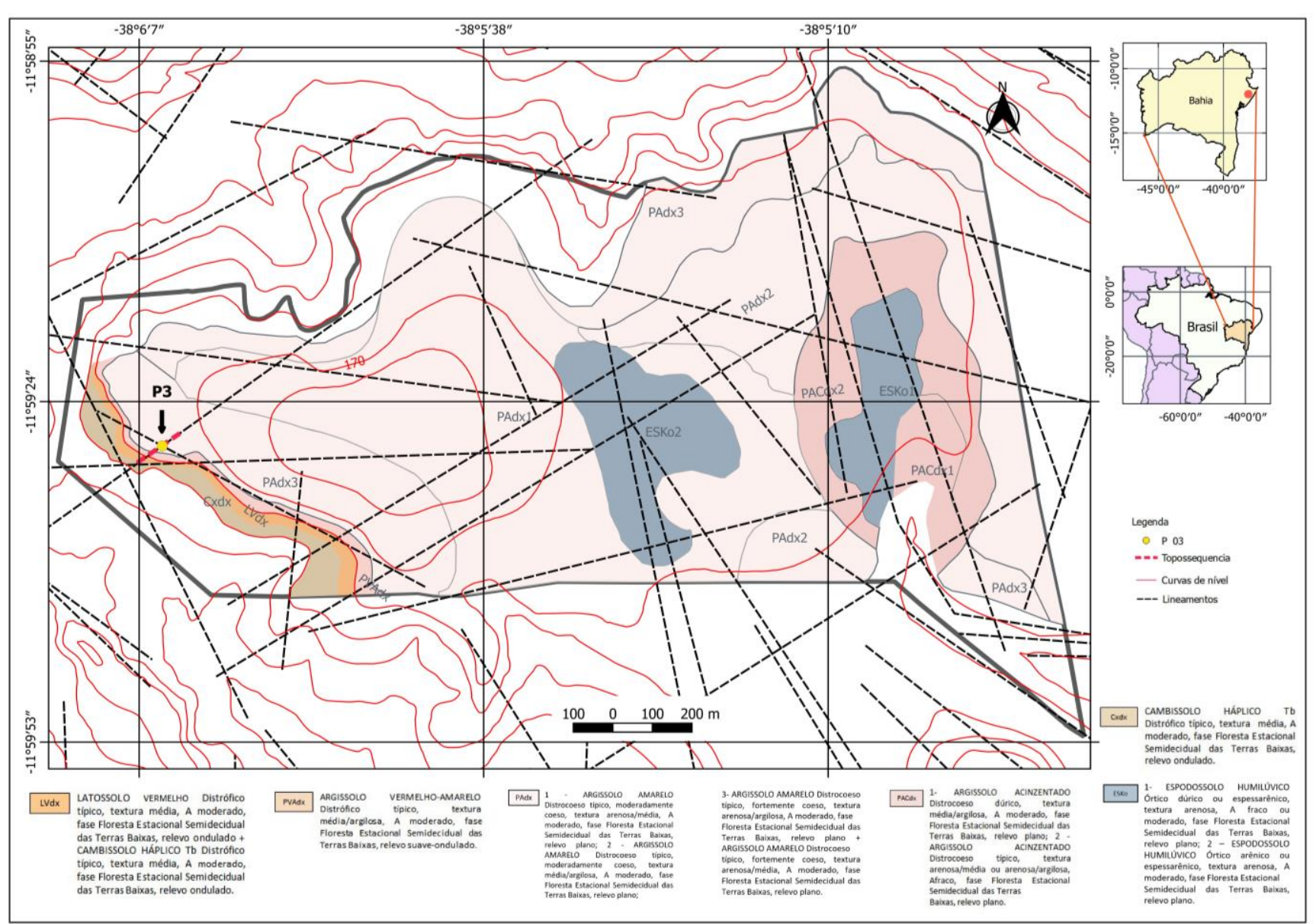

Fonte - Adaptado de COPENER (1987), IBGE (2005). 


\section{CONCLUSÕES}

Os solos vermelhos se formaram a partir do intemperismo de arenitos lamosos conglomeráticos ferruginosos e arenitos lamosos e se transformaram em solos amarelos pela xantização da cobertura pedológica. Em função da instabilidade da hematita em climas úmidos, acredita-se que os solos vermelhos se formaram em condições climáticas mais secas que as atuais e começaram a se transformar em amarelos a partir da umidificação do clima.

Os horizontes coesos começaram a se formar nos solos vermelhos e se tornaram mais endurecidos e espessos com a evolução da cobertura pedológica para amarela, o que ocorreu pari passu com a diminuição dos teores de ferro livre, degradação do plasma argiloso dos horizontes superficiais e avanço da argiluviação.

A cobertura pedológica está passando por um processo de "micropodzolização", devido à influência da neotectônica, responsável pela formação de uma microdepressão fechada que acumula água após episódios pluviosos, criando um ambiente hidromórfico temporário e acentuando a degradação do plasma argiloso dos solos.

\section{AGRADECIMENTOS}

À Bioconsultoria Gestão e Licenciamento Ambiental LTDA por financiar o projeto de pesquisa e à Bahia Pulp por ceder a área de estudo e pelo apoio logístico, em especial a Aline Angeli, Jacyr Mesquita Alves, Dailson Ramalho Lima e William Mattos.

\section{REFERÊNCIAS}

ALMEIDA, J. A; MAÇANEIRO, K.C; KLAMT, E. Mineralogia da fração argila de solos vermelhos com horizontes superficiais brunados do planalto de Lages (SC). Revista Brasileira de Ciência do Solo, 24:815-828, 2000. https://doi.org/10.1590/S0100-06832000000400014

ARAI, M. A Grande Elevação Eustática do Mioceno e Sua Influência na Origem do Grupo Barreiras. Geol. USP Sér. Cient., São Paulo, v.6, n2, p. 1-6, 2006. https://doi.org/10.5327/S1519874X2006000300002

BEAUVAIS, A; TARDY, Y. Formation et degradation des cuirasses ferruginieuses sons climat tropical humide, à la lisière de la forêt équatoriale. C. R. Acad. Sci. Paris, t. 313, Ser. II p. 15391545, 1991.

BEZERRA, F. H. R. Neotectonics in Northeastern Brazil. Thesis Doctor Philosophy, Department of Geological Sciences, UniversityCollege London 1998. 208p.

BRASIL. Ministério das Minas e Energia. Secretaria Geral. Folha SD 24 Salvador: geologia, geomorfologia, pedologia, vegetação, uso potencial da terra. Rio de Janeiro, v. 24, 1981. 624p.

BRINKMAN, R. Ferrolysis, a hydromorphic soil forming process.Geoderma, 3:199-206, 1970. https://doi.org/10.1016/0016-7061(70)90019-4

BUURMAN, P; JONGMANS, A.G. Podzolisation and soil organic matter dynamics. Geoderma, 125 (1-2), p.71-83, 2005. https://doi.org/10.1016/i.geoderma.2004.07.006

CARVALHO, C. C. N. Gênese e transformação de solos em um tabuleiro do recôncavo baiano. Universidade Federal da Bahia, Instituto de Geociências, Salvador, 2001. $116 f$. (Dissertação de Mestrado).

CORRÊA, M. M.; KER, J. C.; BARRÓN, V.; TORRENT, J.; CURI, N.; TORRES, T. C. P. Caracterização física, química, mineralógica e micromorfológica de horizontes coesos e fragipãs de solos vermelhos e amarelos do ambiente tabuleiros costeiros. R. Bras. Ci. Solo, 32:297-313, 2008. https://doi.org/10.1590/S0100-06832008000100028 
CORREA-GOMES, L. C.; UCHA, J. M. ; SILVA, I. C.. Neotectônica. In: BARBOSA, J. S. F.. (Org.). Geologia da Bahia: pesquisa e atualização. 1ed.Salvador: CBPM, 2012, v. 2, p. 497-515.

COSTA JÚNIOR, M. P. Interações morfo-pedogenéticas nos sedimentos do Grupo Barreiras e nos leques aluviais pleistocênicos no Litoral Norte da Bahia - município de Conde. 2008. (Tese de Doutorado).

DUARTE, M. N.; CURI, N.; PÉREZ, D.V.; KAMPF, N.; CLAESSEN, M.E.C. Mineralogia, química e micromorfologia de solos de uma microbacia nos Tabuleiros Costeiros do Espírito Santo. Pesquisa Agropecuária Brasileira, vol.35, n.6, p.1237-1250, 2000. https://doi.org/10.1590/S0100$\underline{204 X 2000000600021}$

DUBROEUCQ, D.; VOLKOFF, B. From oxisol to spodosol and histosol: evolution of the soil mantles in the Rio Negro basin (Amazônia). Catena, Amsterdam, v. 32, p. 245-280, 1998. https://doi.org/10.1016/S0341-8162(98)00045-9

EMBRAPA. EMPRESA BRASILEIRA DE PESQUISA AGROPECUÁRIA. Manual de métodos e análises de solos. 2 edição. Rio de Janeiro, 2011. 230p.

FILIZOLA, H. F.; BOULET, R. Evolution and opening of closed depressions developed in a quartzkaolinitic sedimentary substratum at Taubaté basin (São Paulo, Brazil), and analogy to the slope evolution. Geomorphology, North Carolina, v. 16, n. 4, p. 77-86, 1996. https://doi.org/10.1016/0169-555X(95)00086-K

FORTUNATO, F .F. Sistemas pedológicos nos Tabuleiros Costeiros do Litoral Norte do estado da Bahia: uma evolução controlada por duricrostas preexistentes, neotectônica e mudanças paleoclimáticas do Quaternário. Instituto de Geociências, Universidade Federal da Bahia (Tese de Doutorado), 2004. 366p.

FRITSCH, E.; COX, J.; FITZPATRICK, R. W.Processos hidrogeoquímicos de transformação de solos tropicais: um exemplo do sul da Austrália. Geochimica Brasiliensis, 11(3):243-259,1997.

IBGE. Instituto Brasileiro de Geografia e Estatística. Manual Técnico da Vegetação Brasileira. $2^{\underline{a}}$ Ed. revisada e ampliada. 2012. 271p.

KAMPF, N; CURI, N. Argilominerais em solos brasileiros. In: Tópicos em Ciência do Solo. P.1-54. SBCS, 2003.

KAMPF, N; SCHWERTMANN, U. Relações entre óxidos de ferro e a cor em solos cauliníticos do Rio Grande do Sul. Revista Brasileira Ciência do Solo, 7:27-31,1983.

KLAMT, E; MEURER, J. In: Fundamentos de química do solo. Porto Alegre: Gênesis, 2000. $174 p$.

LAMOTTE, M.; BRAUND, A.; HUMBEL, F. X.; HERBILLON, A. J.; RIEU, M. A hard sandy-loam soil from semi-arid northern Cameroon: Fabric of the groundmass. Eur. J. Soil Sci., 48:213-225, 1997a. https://doi.org/10.1111/j.1365-2389.1997.tb00542.x

LAMOTTE, M.; BRAUND, A.; OHNENSTETTER, D.; ILDEFONSE, P.; PÉDRO, G. A hard sandyloam soil from semi-arid northern Cameroon: Geochemistry and mineralogy of the bonding agent. Eur. J. Soil Sci., 48:227-237, 1997b. https://doi.org/10.1111/j.1365-2389.1997.tb00543.x

RIBEIRO, L. P. Ferralitização do nordeste semi-árido: os solos vermelhos de Jequié - Bahia. Faculdade de Filosofia, Letras e Ciências Humanas, Universidade de São Paulo (Tese de Doutorado), 1982.

RIBEIRO, L. P. Os Latossolos Amarelos do Recôncavo Baiano: gênese, evolução e degradação. Salvador: CADCT/FAPEX, 1998. 99p.

ROSSETTI, D. F.; DOMINGUEZ, J.M.L. Tabuleiros Costeiros. In: BARBOSA, J.S.F. et al. (Eds) Geologia da Bahia: Pesquisa e Atualização. Salvador: UFBA-CBPM, 2012. v.2, p. 365-393. 
SAADI, A. Neotectônica da plataforma brasileira: esboço e interpretações preliminares. Geonomos 1(1): 1-15. 1993. https://doi.org/10.18285/geonomos.v1i1e2.233

SANTOS, R. D.; LEMOS, R.C.; SANTOS, H.G., KER, J.C. \& ANJOS, L.H.C. Manual de descrição e coleta de solos no campo. 5.ed. Campinas, SBCS/EMBRAPA - SNCLS, 2013.

SCHWERTMANN, U. Transformation of hematite to goethite in soils. Nature, 232:624-625, 1971. https://doi.org/10.1038/232624a0

STOOPS, G. Guidelines for analysis and description of soil and regolith thin sections. Soil Sci. Soc. Am., Madison, WI, 2003. 184p.

STUTZER, A. Early stages of podzolisation in young aeolian sediments, western Jutland. Catena, 32, 115-129, 1998. https://doi.org/10.1016/S0341-8162(98)00039-3

VILAS BOAS, G. S. et al. The Barreiras Group in the northeastern coast of the State of Bahia, Brasil: depositional mechanisms and processes. Anais da Academia Brasileira de Ciências, v. 73, n. 3, p. 417-427, 2001. https://doi.org/10.1590/S0001-37652001000300010

Recebido em: 11/02/2018

Aceito para publicação em: 26/11/2019 